\title{
əModulation of Cross-Isothermal Velocities with ENSO in the Tropical Pacific Cold Tongue
}

\author{
AnNa-Lena Deppenmeier, ${ }^{a}$ Frank O. Bryan, ${ }^{a}$ William S. Kessler, ${ }^{\mathrm{b}}$ And LuAnNe Thompson ${ }^{\mathrm{c}}$ \\ ${ }^{a}$ National Center for Atmospheric Research, Boulder, Colorado \\ ${ }^{\mathrm{b}}$ NOAA/Pacific Marine Environmental Laboratory, Seattle, Washington \\ ${ }^{\mathrm{c}}$ University of Washington, Seattle, Washington
}

(Manuscript received 2 September 2020, in final form 12 February 2021)

\begin{abstract}
The tropical Pacific Ocean cold tongue (CT) plays a major role in the global climate system. The strength of the CT sets the zonal temperature gradient in the Pacific that couples with the atmospheric Walker circulation. This coupling is an essential component of the El Niño-Southern Oscillation (ENSO). The CT is supplied with cold water by the Equatorial Undercurrent that follows the thermocline as it shoals toward the east, adiabatically transporting cold water toward the surface. As the thermocline shoals, its water is transformed through diabatic processes, producing water mass transformation (WMT) that allows water to cross mean isotherms. Here, we examine WMT in the cold-tongue region from a global high-resolution ocean simulation with saved budget terms that close its heat budget exactly. Using the terms of the heat budget, we quantify each individual component of WMT (vertical mixing, horizontal mixing, eddy fluxes, and solar penetration) and find that vertical mixing is the single most important contribution in the thermocline and solar heating dominates close to the surface. Horizontal diffusion is much smaller. During El Niño events, vertical mixing, and hence cross-isothermal flow as a whole, are much reduced, whereas, during La Niña periods, strong vertical mixing leads to strong WMT, thereby cooling the surface. This analysis demonstrates the enhancement of diabatic processes during cold events, which in turn enhances cooling of the CT from below the surface.
\end{abstract}

KEYWORDS: Pacific Ocean; ENSO; Ocean dynamics; Diapycnal mixing; Ocean models; Tropical variability

\section{Introduction}

The tropical Pacific Ocean cold tongue (CT) plays a major role in both the mean climate and climate variability. The CT is the main region of energy uptake into the ocean. It supplies buoyancy to the global circulation (Newsom and Thompson 2018; Holmes et al. 2019b) and can influence and modulate the global climate change signal (England et al. 2014). For these reasons, the mean circulation of the equatorial Pacific has historically received considerable attention: from early inferences of upwelling driven by divergence of the Ekman transport (Cromwell 1953) and the discovery of the Equatorial Undercurrent (EUC) (Cromwell et al. 1954), to quantification of mass and heat budgets of the tropical cells enabled by the development of deep ocean moorings along with sparse hydrographic sections (Bryden and Brady 1985; Weisberg and Qiao 2000; Meinen et al. 2001; Johnson et al. 2001).

Sea surface temperature (SST) variability of the CT, which lies at the heart of the El Niño-Southern Oscillation (ENSO), has been the focus of many studies for more than 40 years (Wyrtki 1975; Philander 1990). ENSO is the leading mode of climate variability (Neelin et al. 1998; McPhaden et al. 2006; Chang et al. 2006; Wang et al. 2017) with impacts all over the globe. Understanding the mechanisms that control the strength and variability of the $\mathrm{CT}$ in the tropical Pacific is essential for

\footnotetext{
๑ Denotes content that is immediately available upon publication as open access.
}

Corresponding author: Anna-Lena Deppenmeier, deppenme@ ucar.edu reliable ENSO forecasts (Ji and Leetmaa 1997; Barnston et al. 2012; Tang et al. 2018; Ding et al. 2020) and, given the importance of the eastern tropical Pacific in the global climate system, for well-founded climate projections (Bayr et al. 2019; Samanta et al. 2019).

Although great progress in understanding and modeling the tropical Pacific circulation and ENSO variability has been made (Mechoso et al. 1995; Zelle et al. 2004; Karnauskas et al. 2007; Ray et al. 2018), major questions remain. For example, how does La Niña mechanistically compare with El Niño (Timmermann et al. 2018)? To what degree is SST variability driven by adiabatic (Jin 1997) versus diabatic processes (Lengaigne et al. 2012)? Often, diabatic processes have to be derived from residuals (Meinen and McPhaden 2001, 2000). Here, we employ full heat budgets from a highresolution ocean model to explicitly calculate drivers of diabatic processes.

The vertical branch of the equatorial circulation cannot be measured directly. Historically, an integrated box model approach has been taken to arrive at average upwelling estimates for large control volumes from widely spaced hydrographic sections and sparse direct velocity measurements (Wyrtki 1981; Bryden and Brady 1985; Weisberg and Qiao 2000; Johnson et al. 2001; Meinen et al. 2001). Bryden and Brady (1985) showed that a large component of the net equatorial vertical velocity is associated with the EUC flowing parallel to isotherms as they rise toward the east, that is, a large fraction of the vertical velocity is adiabatic. Estimates of the crossisothermal component of equatorial Pacific upwelling, again over large control volumes, based on this kinematic formulation have been made by Meinen et al. (2001) using hydrographic sections, and geostrophic and Ekman dynamics. Similar to 
Bryden and Brady (1985) they find that the cross-isothermal component of the vertical velocity is a fraction of the total upwelling.

However, (diabatic) ocean vertical mixing has been found to be the dominant cooling term driving SST variability in the equatorial CT on both annual and interannual time scales (Wang and McPhaden 1999, 2000; Moum et al. 2013; Warner and Moum 2019). There is hence a need to investigate diabatic processes and how they change during ENSO conditions.

In this study, we investigate how vertical circulation in the tropics decomposes into diabatic and adiabatic flow, and how the diabatic component changes during ENSO, from global high-resolution ocean model output. We employ the water mass transformation (WMT) framework, which allows us to determine how water is transformed from one water mass class into another. Here, we focus on temperature classes, i.e., water masses within a given temperature interval. In this case WMT consists of water crossing isotherms, hence we examine crossisothermal velocities.

The WMT framework has first been developed by Walin (1982) and further illustrated by Nurser et al. (1999), who attributed the flow of water parcels across isotherms to heating and cooling. In the case of a water mass that is bound by a certain isotherm outcropping around it, heating at the surface (by surface fluxes) has to be balanced by (diffusive) cooling from below (Niiler and Stevenson 1982; Toole et al. 2004; Hieronymus et al. 2014).

Traditionally, WMT investigates heating and cooling terms over a large volume bounded by an isosurface. Building on this, we leverage an implementation of the WMT framework that allows us to calculate local cross-isothermal velocities and attribute them to specific diabatic processes, namely, vertical mixing, solar penetration, and horizontal diffusion. Importantly, it allows us to retain spatial information about the processes.

We focus the analysis at $140^{\circ} \mathrm{W}$, which is representative of the CT (Fig. 2b; Fig. 2 is described in more detail below). We also show results for other longitudes where the TAO/TRITON array (https://www.pmel.noaa.gov/gtmba/pmel-theme/pacific-oceantao) samples both the equator and at off-equatorial locations (indicated with white squares on Figs. 2a,b, below).

\section{Data and method}

\section{a. Model description and experimental design}

We utilize output from an experiment with the Parallel Ocean Program (POP2) ocean model at $0.1^{\circ}$ horizontal resolution, with 10 -m-thick vertical levels in the top $200 \mathrm{~m}$ and spacing increasing toward the bottom. The model configuration is identical to that described in Bryan and Bachman (2015). The current experiment is forced with interannually varying atmospheric conditions derived from the JRA-55 reanalysis (Kobayashi et al. 2015) designated JRA-55do (Tsujino et al. 2018), which spans the period 1958-2018. The experiment is initialized at rest with potential temperature and salinity from the World Ocean Atlas 2013 (Boyer et al. 2013). All of the terms in the temperature budget [see (6), below] at each grid point are saved during runtime as 5-day averages. The analysis presented here is restricted to the 36-yr period 1983-2018, for which full heat budget output is available.

Chassignet et al. (2020) assesses the veracity of the simulation and compares it against other high-resolution global models forced under the same protocol. Here, we present temperature and zonal velocity profiles in comparison to TAO data, both for the mean and for El Niño and La Niña conditions (Fig. 1). The mean zonal flow and temperature structure along the equator are well captured, with the agreement with observations slightly better in the west $\left(170^{\circ} \mathrm{W}\right)$ than in the east $\left(110^{\circ} \mathrm{W}\right.$, Fig. 1$)$. At $140^{\circ} \mathrm{W}$, where we focus most of our analysis, the center of the mean EUC is $20 \mathrm{~m}$ deeper and $10 \mathrm{~cm} \mathrm{~s}^{-1}$ stronger than observed. However, the vertical shear in the upper $40-100 \mathrm{~m}$ is almost identical. The mixed layer in POP2 is slightly deeper than in TAO at the same location, but the thermocline is nearly as steep, while it is a little more diffuse at $110^{\circ} \mathrm{W}$. The total velocity variance (all time scales) in TAO is larger than the total variance in POP2 throughout the water column and at all locations (cf. shading around the velocity profiles in Fig. 1, first row). We examine the differing behavior of temperature and zonal flow between El Niño and La Niña events (identified by red for El Niño and blue for La Niña events) in the second and third rows of Fig. 1 for both POP2 (solid) and TAO (dashed). To identify El Niño and La Niña phases we require an SST anomaly exceeding $\pm 0.4^{\circ} \mathrm{C}$ in the Niño-3.4 index that persists for at least 6 months (respectively marked with red and blue coloring in Fig. 5a). Both the model and the observational products are averaged over the El Niño and La Niña periods identified from the model Niño-3.4 index (choosing an observational Niño-3.4 index for averaging the observational dataset does not change the results significantly). Overall, the model captures the zonal flow and temperature variations well. At $170^{\circ}$ and $140^{\circ} \mathrm{W}$ the EUC strengthens during La Niña compared to El Niño in both POP2 and TAO data, at $110^{\circ} \mathrm{W}$ the difference between the phases is more subtle. Generally, POP2 is more biased during La Niña than during El Niño, featuring a deeper and stronger EUC maximum than in TAO. Similarly, the temperature profiles (Fig. 1, third row) are more biased during La Niña than during El Niño, POP2 does not maintain a steep thermocline especially in the upper $100 \mathrm{~m}$.

\section{b. Analysis formulation}

We diagnose volume transport across isotherms (crossisothermal velocities, denoted $w_{\mathrm{ci}}$ ) to investigate the processes regulating the diabatic component of the vertical circulation in the eastern tropical Pacific. The cross-isothermal velocity, $w_{\mathrm{ci}}$, is defined as the difference between the velocity of the fluid in the direction normal to the isotherm and the velocity of the isotherm itself (Viúdez 2000; Groeskamp et al. 2019)

$$
w_{\mathrm{ci}} \equiv \hat{\mathbf{n}}_{T} \cdot\left(\mathbf{u}-\mathbf{u}^{\mathrm{iso} T}\right)
$$

with temperature $T$, velocity $\mathbf{u}$, and

$$
\hat{\mathbf{n}}_{T}=\frac{\nabla T}{|\nabla T|} .
$$

This cross-isothermal velocity $w_{\mathrm{ci}}$ can be understood as an entrainment velocity that diabatically entrains water into the 

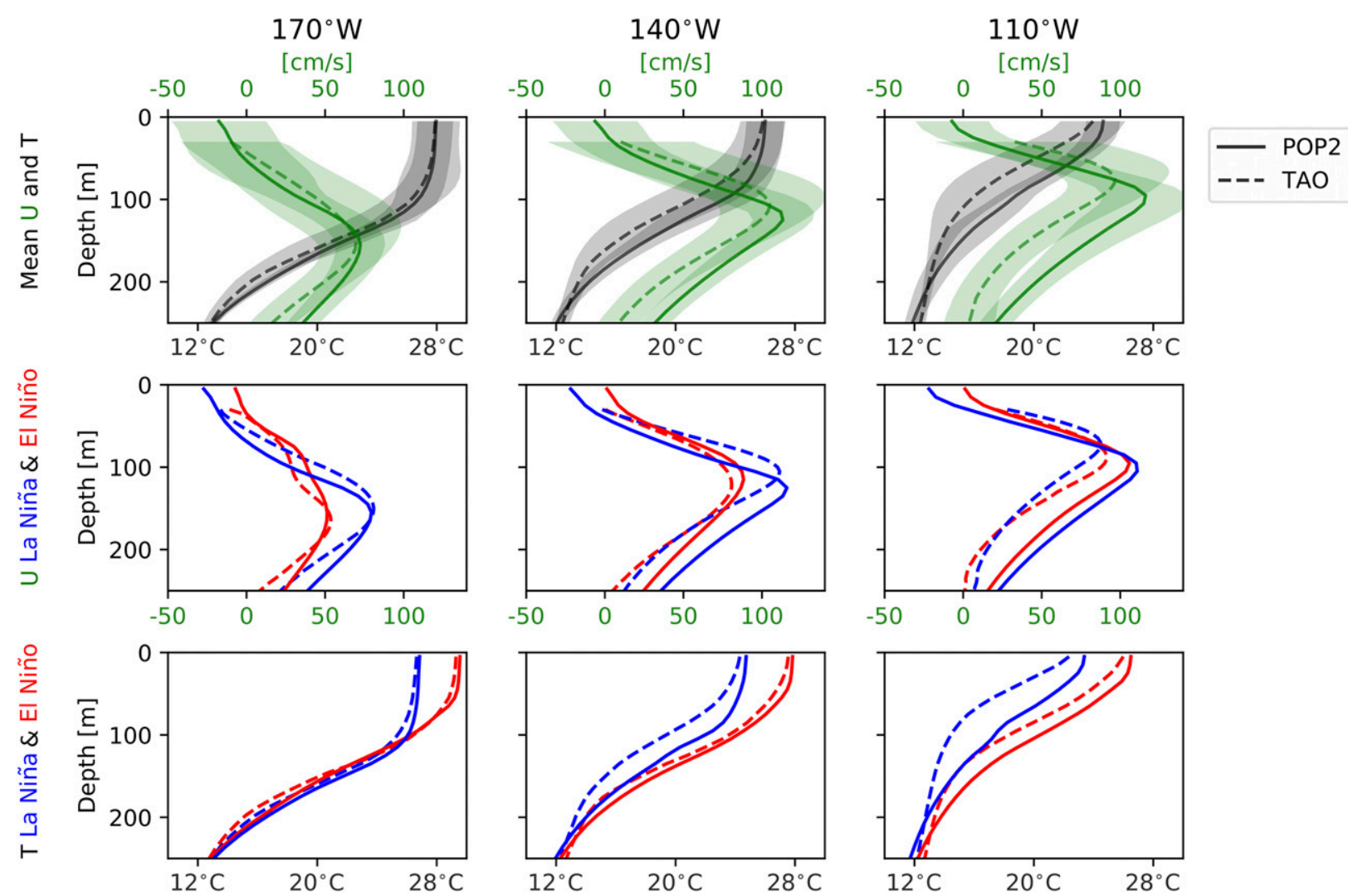

FIG. 1. POP2 and TAO temperature $\left({ }^{\circ} \mathrm{C}\right)$ and velocity $\left(\mathrm{cm} \mathrm{s}^{-1}\right)$ profiles on the equator at $170^{\circ}, 140^{\circ}$, and $110^{\circ} \mathrm{W}$ for (top) the mean and separately for (middle) El Niño and (bottom) La Niña phases. Envelopes around the mean profiles show 1 standard deviation (all time scales). The following years have been chosen for the velocity comparison, according to TAO data availability: from May 1988 until August 2018 for $170^{\circ} \mathrm{W}$, from May 1990 until April 2018 for $140^{\circ} \mathrm{W}$, and from May 1991 until April 2016 for $110^{\circ} \mathrm{W}$. Gaps in TAO data have not been accounted for in sampling the model data. The total POP2 (1983-2018) and TAO records (1988-2020) have been used for the temperature comparison. We note that neither the mean nor the standard deviation of $U$ or $T$ significantly change when choosing shorter periods. The El Niño and La Niña phases are identified from the model Niño-3.4 index shown in Fig. 5.

layer above the given isotherm. It is important to note that this is not equivalent to the entrainment velocity that is used to understand mixed layer heat budgets, since the layer here is defined by an arbitrary moving isotherm rather than a specific depth. We are hence not evaluating a heat budget in a given volume, but rather employing the connection between the heat budget and the volume budget in temperature coordinates to arrive at velocities with which water masses are transformed (across isotherms), and we identify the physical drivers behind this diabatic process. In other words, we investigate what forces water parcels to change their temperature in the Lagrangian sense.

The motion of the isotherm, $\mathbf{u}^{\text {iso } T}$, is obtained by noting that, for an observer on the isotherm,

$$
\begin{aligned}
\frac{\partial T}{\partial t}+\mathbf{u}^{\text {iso } T} \cdot \nabla T & =0, \quad \text { or } \\
\mathbf{u}^{\text {iso } T} \cdot \nabla T & =-\frac{\partial T}{\partial t},
\end{aligned}
$$

where $t$ is time. Using the definition of the cross-isothermal direction $\hat{\mathbf{n}}_{T}$ and substituting (4) in (1) gives

$$
w_{\mathrm{ci}}=\frac{1}{|\nabla T|}\left(\mathbf{u} \cdot \nabla T+\frac{\partial T}{\partial t}\right)=\frac{1}{|\nabla T|} \frac{D T}{D t} .
$$

Expression (5) relates the conservation of volume to the conservation of heat, a form of water mass transformation analysis. The more conventional expressions for water mass transformation relating transports to integrals of diabatic fluxes over control volumes bounded by isotherms or isopycnals (Walin 1982) can be derived from (5) (Groeskamp et al. 2019). We choose to work with the form above to retain local information allowing us to identify where and under what flow conditions parcels cross isotherms.

This framework allows us to identify the specific processes that contribute to cross-isothermal motion by connecting the cross-isothermal velocity to the heat budget. The conservation of potential temperature (henceforth when referring to temperature we are working with potential temperature) in POP2 (Smith et al. 2010) is given by

$$
\frac{D T}{D t}=\frac{\partial}{\partial z}\left[\kappa\left(\frac{\partial T}{\partial z}-\Gamma\right)\right]+\nabla^{2}\left(B_{h} \nabla^{2} T\right)+\frac{\partial}{\partial z}\left(\frac{1}{\rho_{0} c_{p}} I\right)
$$


with surface boundary conditions

$$
\begin{aligned}
& \left.\kappa \frac{\partial T}{\partial z}\right|_{z=0}=Q_{\mathrm{ns}} \\
& \left.I\right|_{z=0}=Q_{s}
\end{aligned}
$$

where $\kappa$ is the vertical diffusivity, $\kappa \Gamma$ is the countergradient flux in the boundary layer [both are diagnosed with the $K$-profile parameterization (KPP; Large et al. 1994); the combined expression in the square brackets in (6) makes $J], B_{h}$ is the horizontal hyperdiffusivity (hence the second term on the right-hand side is horizontal diffusion $\mathbf{H}_{\text {diff }}$ ), $\rho_{0}$ is density, $c_{p}$ is the specific heat of seawater, $I$ is the downward radiation flux into the water column with depth $z, Q_{\mathrm{ns}}$ is the net nonsolar component of the surface heat flux, and $Q_{s}$ is the surface solar heat radiation flux. Penetrative solar radiation that is based on climatological chlorophyll levels is calculated according to Ohlmann (2003), using a double exponential. Substituting the right-hand side of (6) into (5) gives

$$
w_{\mathrm{ci}}=\frac{1}{\rho_{0} c_{p}|\nabla T|}\left(\frac{\partial J}{\partial z}+\nabla \cdot \mathbf{H}_{\mathrm{diff}}+\frac{\partial I}{\partial z}\right),
$$

where we abbreviate the vertical and horizontal diffusive heat fluxes with $J$ and $\mathbf{H}_{\text {diff }}$, respectively.

The derivation thus far has considered the state variables and fluxes to be instantaneous quantities. Practical applications using either observations or model output would more typically start with quantities averaged and sampled over some finite time and space scales. In the analysis below, we evaluate $w_{\mathrm{ci}}$ using the temperature tendency, advective and diabatic fluxes saved as 5-day averages accumulated during the model integration. With the available archived model output, we can calculate each term in (6) explicitly and satisfy the balance to roundoff error. Beginning with these averages, we use a modified version of (8) that represents the 5-day mean crossisothermal transport across the 5-day mean position of the isotherm,

$$
\begin{aligned}
& \bar{w}_{\mathrm{ci}}=\frac{1}{|\nabla \bar{T}|}\left(\bar{u} \cdot \nabla \bar{T}+\frac{\partial \bar{T}}{\partial t}\right) \\
& =\frac{1}{\rho_{0} c_{p}|\nabla \bar{T}|}\left[\frac{\partial \bar{J}}{\partial z}+\nabla \cdot \bar{H}_{\mathrm{diff}}+\frac{\partial \bar{I}}{\partial z}-\rho_{0} c_{p} \nabla \cdot\left(\overline{\mathbf{u}^{\prime} T^{\prime}}\right)\right]+\text { hot }, \\
& \begin{array}{cccc}
\uparrow & \uparrow & \uparrow & \uparrow \\
w_{\mathrm{ci}}^{\text {vmix }} & w_{\mathrm{ci}}^{\text {hdiff }} & w_{\mathrm{ci}}^{\text {solar }} & w_{\mathrm{ci}}^{\text {cov }}
\end{array}
\end{aligned}
$$

where the additional term in the square brackets $\left(w_{\mathrm{ci}}^{\mathrm{cov}}\right)$ is the resolved eddy flux of temperature on time scales less than 5 days, and higher-order terms ("hot") arise from covariance between the diabatic fluxes and the magnitude of the temperature gradient on sub-5-day time scales. With the available output we can compute the resolved sub-5-day eddy flux but not the higher-order terms. In the text below, we refer to the contribution of a physical process on the cross-isothermal velocities with the notation $w_{\mathrm{ci}}^{\text {solar }}, w_{\mathrm{ci}}^{\mathrm{vmix}}$, and so forth.
The velocities $w_{\mathrm{ci}}^{\text {solar }}$ and $w_{\mathrm{ci}}^{\mathrm{vmix}}$ quantify the impact of the vertical flux divergence, rather than the flux itself [see (9)]. For solar penetration, the downward flux steadily reduces with depth, hence the divergence maintains one sign. This is not true for the vertical divergence of the turbulent heat flux due to vertical mixing. For the eastern Pacific CT, the heat flux due to vertical mixing typically peaks below the surface and then further decreases with depth; thus the divergence (and therefore $w_{\mathrm{ci}}^{\mathrm{vmix}}$ ) is minimum where the heat flux is maximum. Crossisothermal velocity $w_{\mathrm{ci}}^{\mathrm{vmix}}$ can therefore have both signs. Both solar penetration and vertical mixing induce cross-isothermal velocities through their vertical divergence. We note that when considering the cross-isothermal direction the resulting velocities can be horizontal, depending on the direction of the temperature gradient. Consider solar penetration near the surface at a vertically unstratified location. Warming the water parcel means that its location relative to the isotherm changes, from the cold side to the warm side.

The diagnostics in (9) are readily evaluated at the model grid points, for both the total $w_{\mathrm{ci}}$ [first row/equality in (9)], and for the individual terms [second row/equality in (9)]. In the analysis that follows we present results in temperature coordinates. The remapping is performed by monotonic cubic spline interpolation of each term on both sides of (9) for each 5-day average prior to any additional averaging.

We examine which processes control WMT in the CT. We present results for $5^{\circ} \mathrm{S}-5^{\circ} \mathrm{N}$ at $140^{\circ} \mathrm{W}$, and we show the longitudinal dependence of $w_{\text {ci }}$ for the mean field. We further examine how $w_{\mathrm{ci}}$ and its drivers differ between El Niño and La Niña events at $140^{\circ} \mathrm{W}$. Note that the mechanisms remain the same both west and east of $140^{\circ} \mathrm{W}$ with the same modulations as seen in the mean field. We hence only present $140^{\circ} \mathrm{W}$ for the detailed analysis.

\section{Results}

At $140^{\circ} \mathrm{W}$, in the climatological mean, cross-isothermal velocities $w_{\mathrm{ci}}$ are positive across the equator, indicating that cold water is transformed into warmer water. Cross-isothermal velocity $w_{\mathrm{ci}}$ is maximum on the equator between $19^{\circ} \mathrm{C}$ and $25^{\circ}$ with velocities up to $0.5 \mathrm{~m} \mathrm{day}^{-1}$ (Fig. $2 \mathrm{c}$ ). In the warmer temperature classes, above $22^{\circ} \mathrm{C}$, WMT also occurs within $1^{\circ}$ of latitude off the equator to the north and south. Above $24^{\circ} \mathrm{C}$, the maximum cross-isothermal velocity does not occur on the equator; rather, it occurs poleward of $1^{\circ}$ (Fig. 2c). A significant amount of WMT also occurs at temperatures higher than $26^{\circ} \mathrm{C}$ off the equator. Hatching in Fig. 2c implies that the isotherms exist during less than $50 \%$ of the time record. The impact of temporarily existing isotherms on the results is further explained in section 4 .

In the thermocline, $w_{\mathrm{ci}}$ is nearly vertical; within the mixed layer, contours of constant temperature are nearly vertical, making mixed layer $w_{\mathrm{ci}}$ nearly horizontal. This is illustrated by the shape of the isotherms in Fig. $2 \mathrm{~d}$ : the $18^{\circ}-24^{\circ} \mathrm{C}$ isotherms are approximately horizontal, making $w_{\mathrm{ci}}$ approximately vertical. Isotherms above $24^{\circ} \mathrm{C}$ tilt, indicating that $\hat{\mathbf{n}}_{T}$ as defined in (2) has a horizontal component. A comparison between the Eulerian (strictly vertical; $w$ ) velocity and the cross isothermal velocity $w_{\mathrm{ci}}$ (Figs. 2c,d) shows that both are strongest in the 

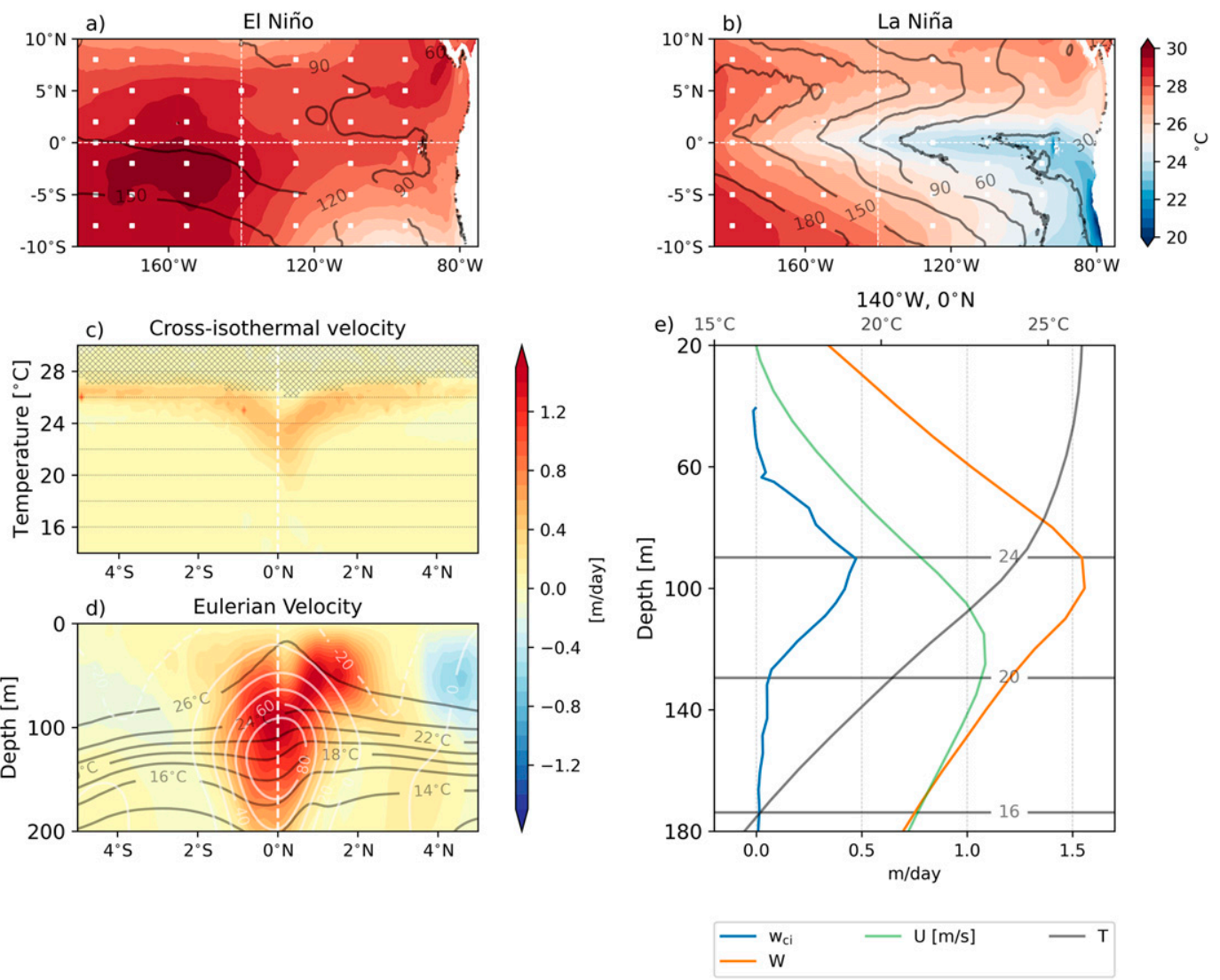

FIG. 2. Sea surface temperature (color shading) during example (a) El Niño (1997/98) and (b) La Niña years (1988/89), with the depth (m) of the $22^{\circ} \mathrm{C}$ isotherm indicated by the gray isotherms. Also shown are the 36 -yr time averages of (c) cross-isothermal velocity $w_{\mathrm{ci}}$ in temperature space $\left(\mathrm{m} \mathrm{day}^{-1}\right)$ and (d) Eulerian vertical velocity in depth space $\left(\mathrm{m} \mathrm{day}^{-1}\right)$ [with isotherms in dark contours (spacing $2^{\circ} \mathrm{C}$ ) and zonal velocity in white contours (spacing $20 \mathrm{~cm} \mathrm{~s}^{-1}$ )] across the equator from $5^{\circ} \mathrm{S}$ to $5^{\circ} \mathrm{N}$ at $140^{\circ} \mathrm{W}$, and (e) profiles of cross-isothermal velocity $\left(\mathrm{m} \mathrm{day}^{-1}\right)$, temperature $\left({ }^{\circ} \mathrm{C}\right)$, and Eulerian vertical $\left(\mathrm{m} \mathrm{day}^{-1}\right)$ and zonal $\left(\mathrm{m} \mathrm{s}^{-1}\right)$ velocities at $0^{\circ}, 140^{\circ} \mathrm{W}$ in depth space. Hatching in (c) corresponds to isotherms that are present for less than $50 \%$ of the time. All panels display POP2 model output and derived quantities.

thermocline between $1^{\circ} \mathrm{S}$ and $1^{\circ} \mathrm{N}$ and that both display a minimum on the equator near the surface.

The Eulerian velocity $w$ is at least 3 times as large in the thermocline as the cross-isothermal velocity $w_{\mathrm{ci}}$, consistent with findings by Meinen et al. (2001) and Bryden and Brady (1985). This is also illustrated by the profiles at $0^{\circ}, 140^{\circ} \mathrm{W}$ (Fig. 2e). Both velocities peak just above the core of the EUC, where water flows east along upward sloping isotherms and where strong shear can foster mixing (Moum et al. 1989; Lien et al. 1995; Moum and Nash 2009; Smyth and Moum 2013), which promotes WMT. Here, we confirm earlier studies that found upward motion in the equatorial Pacific consists mostly of adiabatic flow along isotherms. Like others, however, we also find that a considerable part of the upward motion is diabatic (cf. diabatic $w_{\mathrm{ci}}$ and total vertical velocities in Fig. 2e) such that diabatic processes play a primary role in supplying cold water to the mixed layer (Meinen et al. 2001; Bryden and Brady 1985; Weisberg and Qiao 2000).

The cross-isothermal velocity $w_{\mathrm{ci}}$ cross section at $140^{\circ} \mathrm{W}$ (Fig. 2c) is very similar to that of other locations in the CT: centered on the equator on the colder isotherms, splitting into two maxima off the equator in the warmer isotherms (Fig. 3). The isotherms with large $w_{\mathrm{ci}}$ at each longitude are constrained by the location of the EUC maximum at each longitude, hence we find $w_{\mathrm{ci}}$ in warmer waters in the west and colder waters in the east. The maximum $w_{\mathrm{ci}}$ is centered north of the equator west of $125^{\circ} \mathrm{W}$, and south of the equator east of $125^{\circ} \mathrm{W}$.

The main drivers of WMT in the equatorial Pacific at $140^{\circ} \mathrm{W}$ are $w_{\mathrm{ci}}^{\text {solar }}$ and $w_{\mathrm{ci}}^{\text {vmix }}$ (Fig. 4). Cross-isothermal velocity $w_{\mathrm{ci}}^{\text {hdiff }}$ is ordersof-magnitude smaller than the other contributions (not shown), and eddy rectification effects are also insignificant in the mean derived from 5-day averaged output [not shown; note that here "eddies" refers to resolved small-scale transient motion on time scales of less than 5 days that are relatively weak; tropical instability waves (TIWs) are resolved at the time scales of our calculation, and their effect is included explicitly in the terms in the second line in (9) and implicitly through their effect on velocity shear in the mixing terms $w_{\mathrm{ci}}^{\mathrm{vmix}}$ and $\left.w_{\mathrm{ci}}^{\text {hdiff }}\right]$.

Near the surface, $w_{\mathrm{ci}}^{\mathrm{vmix}}$ and $w_{\mathrm{ci}}^{\text {solar }}$ largely cancel (cf. the $w_{\mathrm{ci}}$ signal near the hatched region with the signals of $w_{\mathrm{ci}}^{\mathrm{vmix}}$ and 


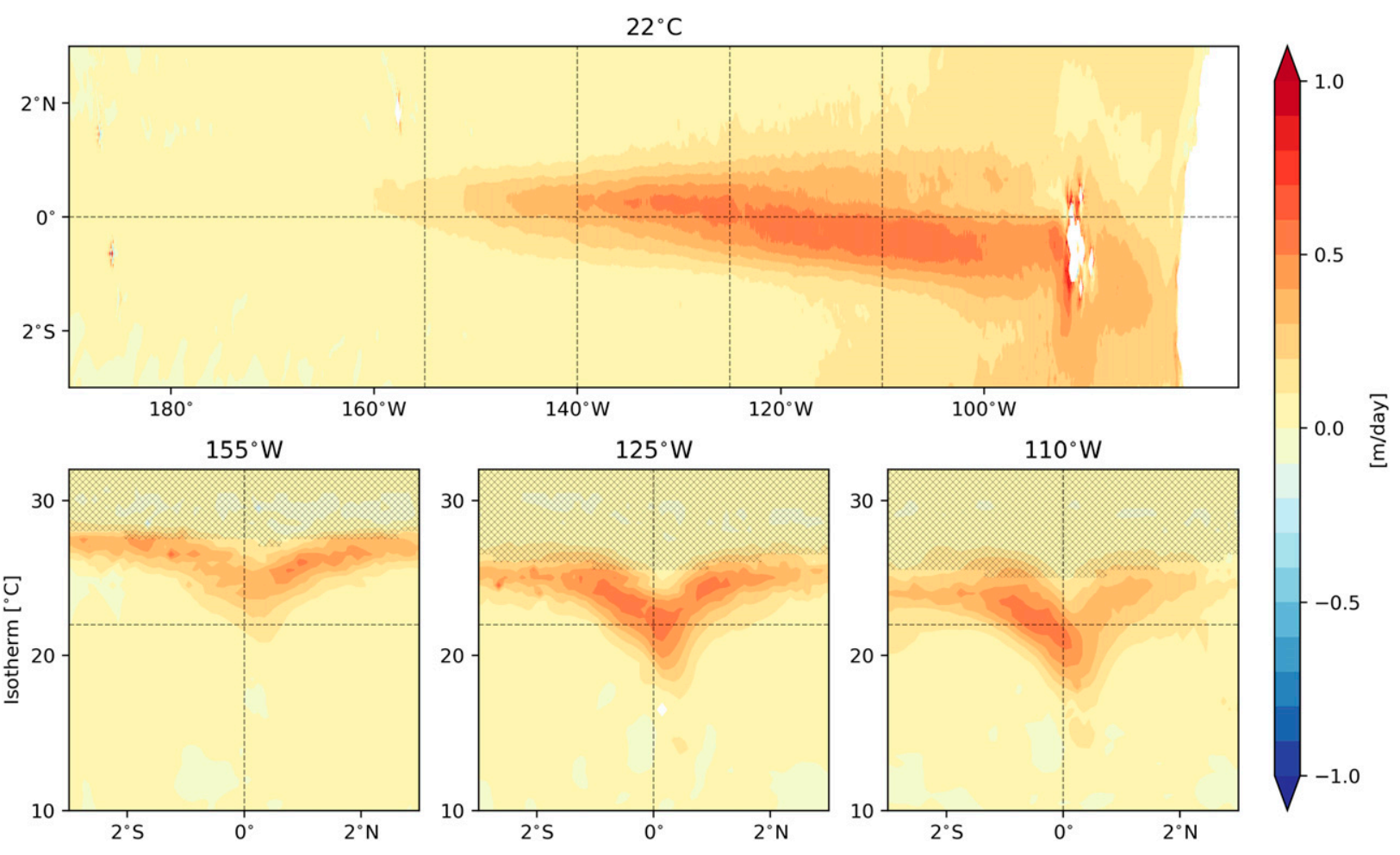

FIG. 3. (top) The 36-yr time averages of cross-isothermal velocity $w_{\mathrm{ci}}$ in POP2 in temperature space ( $\left.\mathrm{m}^{\mathrm{day}}{ }^{-1}\right)$ as in Fig. $2 \mathrm{c}$ across the $22^{\circ} \mathrm{C}$ isotherm in the equatorial Pacific between $3^{\circ} \mathrm{S}$ and $3^{\circ} \mathrm{N}$ and from the South American coast to $170^{\circ} \mathrm{E}$. (bottom) Cross sections for (left) $155^{\circ}$, (center) $125^{\circ}$, and (right) $110^{\circ} \mathrm{W}$, with hatching to indicate isotherms that exist less than $50 \%$ of the time.

$w_{\mathrm{ci}}^{\text {solar }}$ near the hatched region in Fig. 4). The $w_{\mathrm{ci}}^{\text {solar }}$ acts to warm (Fig. 4d) the surface and therefore moves water parcels from colder to warmer classes, while $w_{\mathrm{ci}}^{\mathrm{vmix}}$ opposes $w_{\mathrm{ci}}^{\text {solar }}$ and cools the surface, causing water parcels to move from warmer to colder isotherms [Fig. 4b, negative (blue) signal]. In shallow layers where isotherms exist more than $50 \%$ of the time (not hatched in Fig. 4), warming by solar penetration exceeds the cooling effect of vertical mixing, leading to an overall positive signal. Note that $w_{\mathrm{ci}}$ very close to the surface, i.e., in the warmest isotherms, is nearly poleward, because the surface temperature gradient is dominantly meridional rather than vertical.

In the thermocline the influence of solar radiation is weak. At the $24^{\circ} \mathrm{C}$ isotherm on the equator and $140^{\circ} \mathrm{W} w_{\mathrm{ci}}^{\text {vmix }}$ is the dominant (and in fact single) driver of water parcels moving from colder to warmer classes (Fig. 4b). Throughout, the sum of $w_{\mathrm{ci}}^{\mathrm{vmix}}$ and $w_{\mathrm{ci}}^{\text {solar }}$ almost entirely recovers the signal of $w_{\mathrm{ci}}$ (cf. Figs. $4 \mathrm{a}, \mathrm{c})$. Thus, in the mean, $w_{\mathrm{ci}}^{\mathrm{vmix}}$ drives WMT across the thermocline, bringing colder water up in the thermocline, which causes cross-isothermal velocities of up to one-third of the total Eulerian vertical velocity (Fig. 2e; compare the blue and orange lines).

The strength of $w_{\mathrm{ci}}$ strongly depends on the phase of ENSO. We define El Niños in our simulation (marked in red; Fig. 5a) and La Niñas (marked in blue) when a warm/cold SST anomaly above/below $\pm 0.4^{\circ} \mathrm{C}$ persists for at least 6 months. In the following calculations, we take averages over all events per category during the 36-yr record again focusing on the results at $140^{\circ} \mathrm{W}$.
During neutral conditions (Fig. 5c), WMT occurs down to $20^{\circ} \mathrm{C}$ with $w_{\text {ci }}$ of up to $1 \mathrm{~m} \mathrm{day}^{-1}$. During La Niña (Fig. $5 \mathrm{~d}$ ), WMT is strengthened and extends down to $18^{\circ} \mathrm{C}$, while during El Niño WMT transformation almost shuts down (Fig. 5b). For all three conditions of ENSO the balance described for the mean still holds: $w_{\mathrm{ci}}^{\text {solar }}$ drives WMT in the shallowest layer, which is largely balanced by $w_{\mathrm{ci}}$ of opposite sign arising from $w_{\mathrm{ci}}^{\mathrm{vmix}}$ (Figs. 5e,h,f,i,g,j). In the thermocline, for temperatures between $20^{\circ}$ and $25^{\circ} \mathrm{C}$ near the equator, $w_{\mathrm{ci}}^{\mathrm{vmix}}$ is responsible for nearly all cross-isothermal velocity. Cross-isothermal velocity $w_{\mathrm{ci}}^{\mathrm{vmix}}$ is increased during La Niña (Fig. $5 \mathrm{~g}$ ) and decreased during El Niño (Fig. 5e) when compared to neutral conditions (Fig. 5f). The variability of $w_{\mathrm{ci}}^{\mathrm{vmix}}$ explains the signal in $w_{\mathrm{ci}}$ (Figs. $5 \mathrm{~b}-\mathrm{d}$ ).

To illustrate in more detail the dependence of the WMT on ENSO, we show an example of the evolution of individual La Niña and El Niño events (Fig. 6). During La Niña, in the cooling phase and during the phase in which cold sea surface temperatures are maintained (SST in Fig. 6a, blue and orange lines; $w_{\mathrm{ci}}$ in Figs. $6 \mathrm{~b}$ and $6 \mathrm{c}$ ), cross-isothermal velocities are large and are driven by $w_{\mathrm{ci}}^{\mathrm{vmix}}$ (similar to what is seen in Fig. 5). When SST begins to rise at the end of a La Niña (Fig. 6a, green line; Fig. $\left.6 \mathrm{~d}, w_{\mathrm{ci}}\right)$, the $w_{\mathrm{ci}}$ reduces as the surface warms. During El Niño events (Figs. $6 \mathrm{f}-\mathrm{i}$ ) in the warming and the warm phase (SST in Fig. 6f, blue and orange lines; $w_{\mathrm{ci}}$ in Figs. $6 \mathrm{~g}$ and $6 \mathrm{~h}$ ), there is little WMT below the shallow surface layer, allowing the sea surface to warm. During the decay of the warm SST anomaly, $w_{\text {ci }}$ grows, leading to surface cooling [Fig. 6f, green line (SST); Fig. 6i, $w_{\text {ci }] \text {. }}$ 

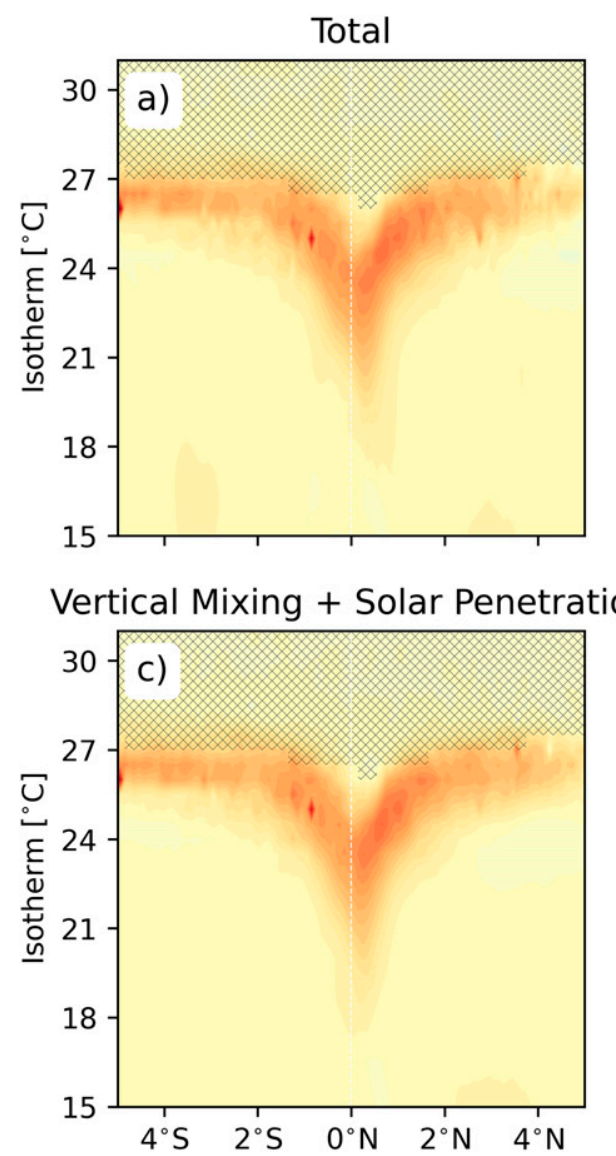

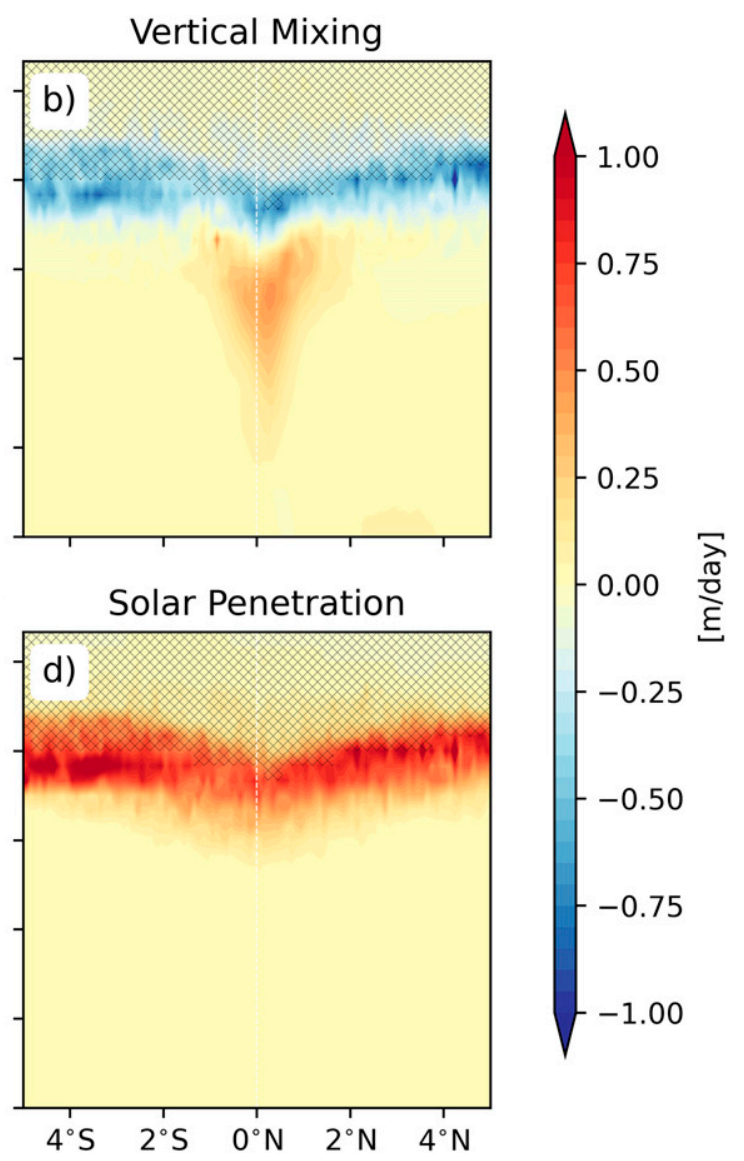

FIG. 4. Main drivers of the cross-isothermal velocity $w_{\text {ci }}$ calculated according to (8) from the POP2 full heat budget output, in temperature space averaged over the 36-yr-long time series. Terms shown are (a) total crossisothermal velocity $w_{\mathrm{ci}}$, (b) cross-isothermal velocity attributable to vertical mixing $w_{\mathrm{ci}}^{\mathrm{vmix}}$, (d) solar penetration $w_{\mathrm{ci}}^{\text {solar }}$, and (c) the sum of $w_{\mathrm{ci}}^{\mathrm{vmix}}$ and $w_{\mathrm{ci}}^{\text {solar }}$. Eddy fluxes and horizontal diffusion are not shown; they are orders of magnitude smaller than the terms shown. Hatching shows the region where isotherms exist less than $50 \%$ of the time.

The time series of $w_{\mathrm{ci}}\left(0^{\circ}, 140^{\circ} \mathrm{W}\right.$, color coded according to the phase of the Niño-3.4 SST anomaly time series) show that the above-described examples are typical. During La Niña conditions, enhanced WMT occurs across the $22^{\circ} \mathrm{C}$ isotherm (blue, Fig. 6j), while during El Niño conditions cross-isothermal velocity diminishes (red, Fig. 6j). This is also true for other isotherms in the thermocline (not shown). The dependence of WMT on ENSO also depends on longitude (Fig. 6k). While the ENSO signal of $w_{\mathrm{ci}}$ averaged over temperature classes are relatively weak in the far eastern extent of the basin, the area between $110^{\circ}$ and $170^{\circ} \mathrm{W}$ shows distinct differences depending on the ENSO condition (Fig. 6k). Cross-isothermal velocity $w_{\mathrm{ci}}$ is enhanced during La Niña throughout this longitude range and is reduced during El Niño.

In the thermocline, ENSO related $w_{\mathrm{ci}}$ modulation at $0^{\circ}$, $140^{\circ} \mathrm{W}$ is entirely due to $w_{\mathrm{ci}}^{\mathrm{vmix}}$ (Figs. 7a,b). In the transition from El Niño to neutral conditions to La Niña conditions $w_{\mathrm{ci}}$ strengthens and occurs at colder isotherms (Figs. 7a,b). For all times, most of the WMT occurs between 60- and 120-m depth (Fig. 7b). During La Niña, the region of water mass transformation expands down to $160 \mathrm{~m}$ (Fig. $7 \mathrm{~b}$, or $20^{\circ}-16^{\circ} \mathrm{C}$, Fig. $7 \mathrm{a}$ ).
To understand $w_{\mathrm{ci}}^{\mathrm{vmix}}$ variability we examine the vertical heat flux due to turbulence $(J)$ and its divergence $\partial J / \partial z$. The $w_{\mathrm{ci}}^{\mathrm{vmix}}$ is calculated as follows:

$$
w_{\mathrm{ci}}^{\mathrm{vmix}}=\frac{1}{\rho c_{p}|\nabla T|} \frac{d J}{d z}
$$

The vertical heat flux is enhanced throughout the thermocline during La Niña, and penetrates deeper in $z$ space (Fig. 7c, solid lines). This results in the heat flux divergence $\partial J / \partial z$ penetrating into deeper layers during La Niña, whereas $\partial J / \partial z$ is greatly reduced during El Niño (Fig. 7c, dashed lines).

The heat flux $J$ calculated by the KPP mixing scheme below the mixed layer is dependent on both the vertical temperature gradient and the diffusivity $\kappa$ :

$$
J=\kappa \frac{d T}{d z} .
$$

Comparing the temperature structure among ENSO conditions reveals that the temperature gradient contribution to the heat flux $J$ is reduced during La Niña in most places of the 
(a)

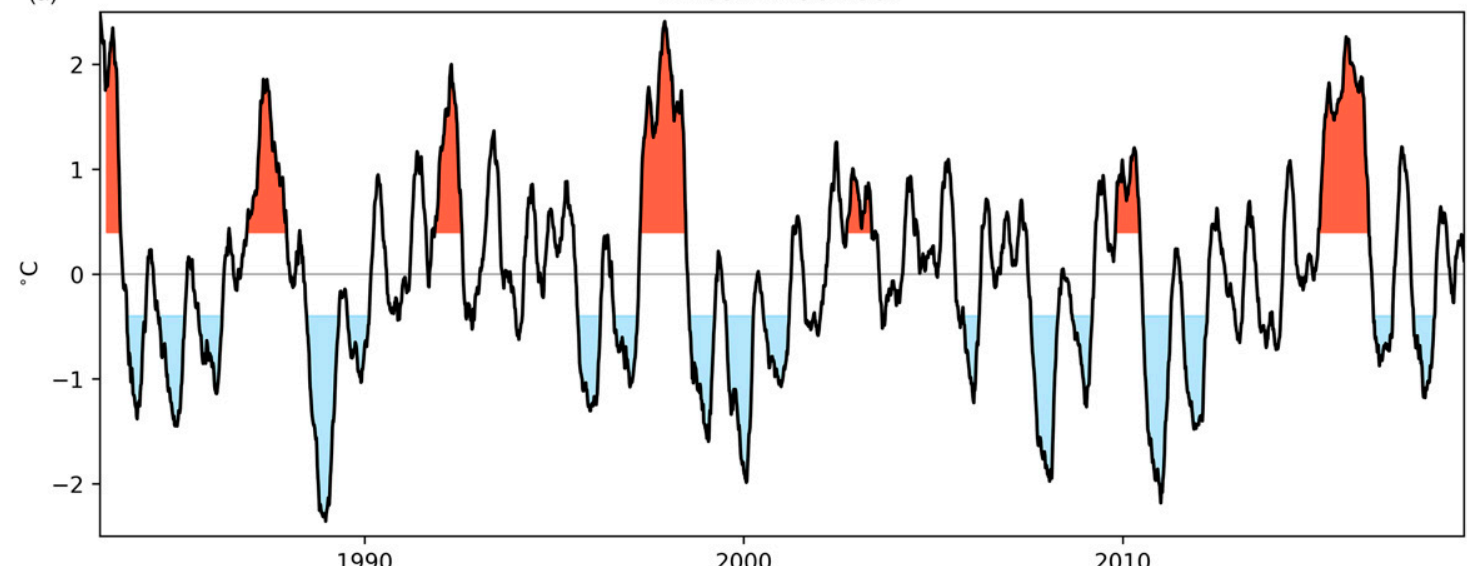

(b)

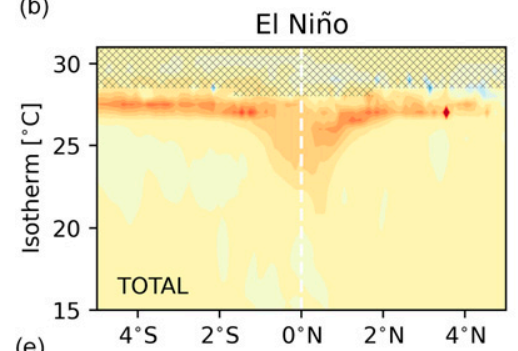

(e)
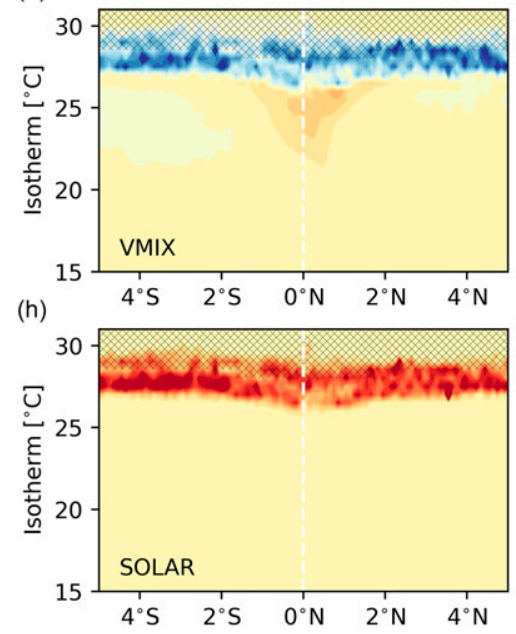

(c)

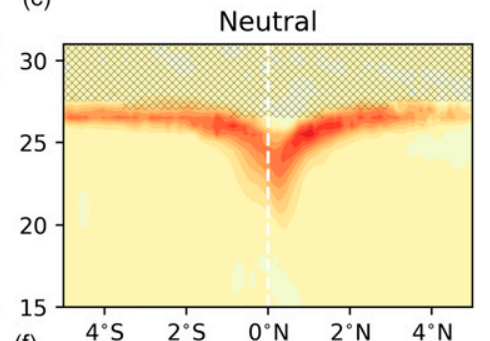

(f)
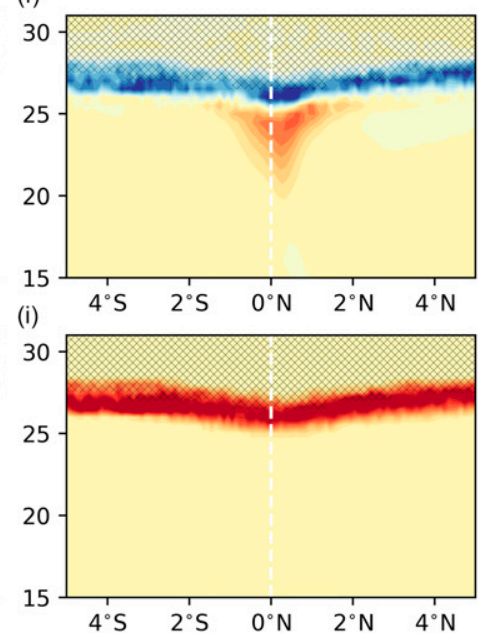

(d)

La Niña
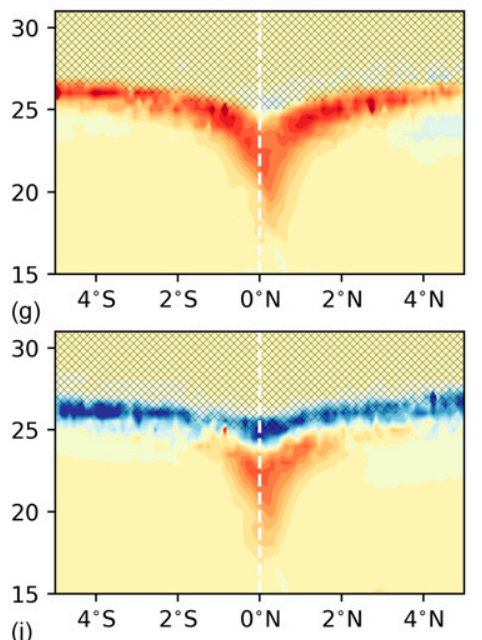

0.3

$\frac{\text { बे }}{\mathrm{\varepsilon}}$

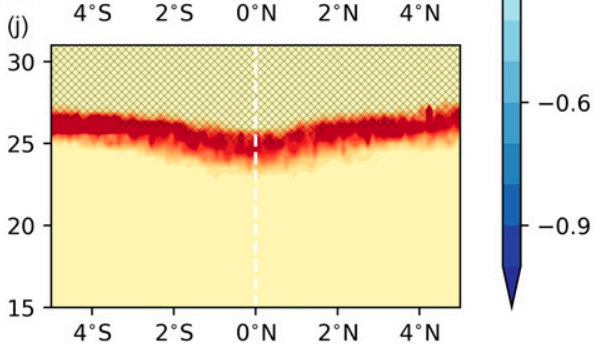

FIG. 5. (a) Niño-3.4 index in the forced simulation, Also shown are (b)-(d) $w_{\mathrm{ci}}$, (e)-(g) $w_{\mathrm{ci}}^{\mathrm{vmix}}$, and (h)-(j) $w_{\mathrm{ci}}^{\text {solar }}$ for (left) El Niño, (center) neutral conditions, and (right) La Niña, corresponding to the phases used for the averaging marked on the Niño-3.4 time series in (a) (red for El Niño, white for neutral, and blue for La Niña). Cross-isothermal velocity $w_{\mathrm{ci}}$ is calculated according to the first line of (9), and $w_{\mathrm{ci}}^{\mathrm{vmix}}$ and $w_{\mathrm{ci}}^{\text {solar }}$ are calculated from the first and third terms of the second line of (9), respectively. All panels display POP2 model output and derived quantities.

water column (Fig. 7d), especially in comparison to neutral conditions. The narrow range of the maximum of the EUC is the exception, here both neutral conditions and La Niña $\partial T / \partial z$ are larger than during El Niño, with La Niña $\partial T / \partial z$ slightly larger than neutral. The latter difference, however, is small.

The prominent factor leading to increased $J$ and $\partial J / \partial z$ at the depth of the EUC maximum is the strong increase in diffusivity $\kappa$ (Fig. 7e, solid lines). At depths where $\partial T / \partial z$ is reduced $(\approx 110-150 \mathrm{~m}$; Fig. $7 \mathrm{~d})$, the increase in $\kappa$ overcomes the reduced temperature gradient and leads to an overall increase in $J$ and $\partial J / \partial z$ during La Niña.

The mean vertical current shear of the zonal velocity component (Fig. 7e, dashed lines) shows the reason for the increased $\kappa$ : enhanced vertical shear penetrates deeper into the ocean column during La Niña, which favors an increase in vertical mixing (Warner and Moum 2019).

The increase in total shear squared $S^{2}$ during La Niña (Fig. 8c) leads to a reduced gradient Richardson number $\mathrm{Ri}=0.8\left(\mathrm{Ri}=N^{2} / S^{2}\right.$, where $N$ is the Brunt-Väisälä 

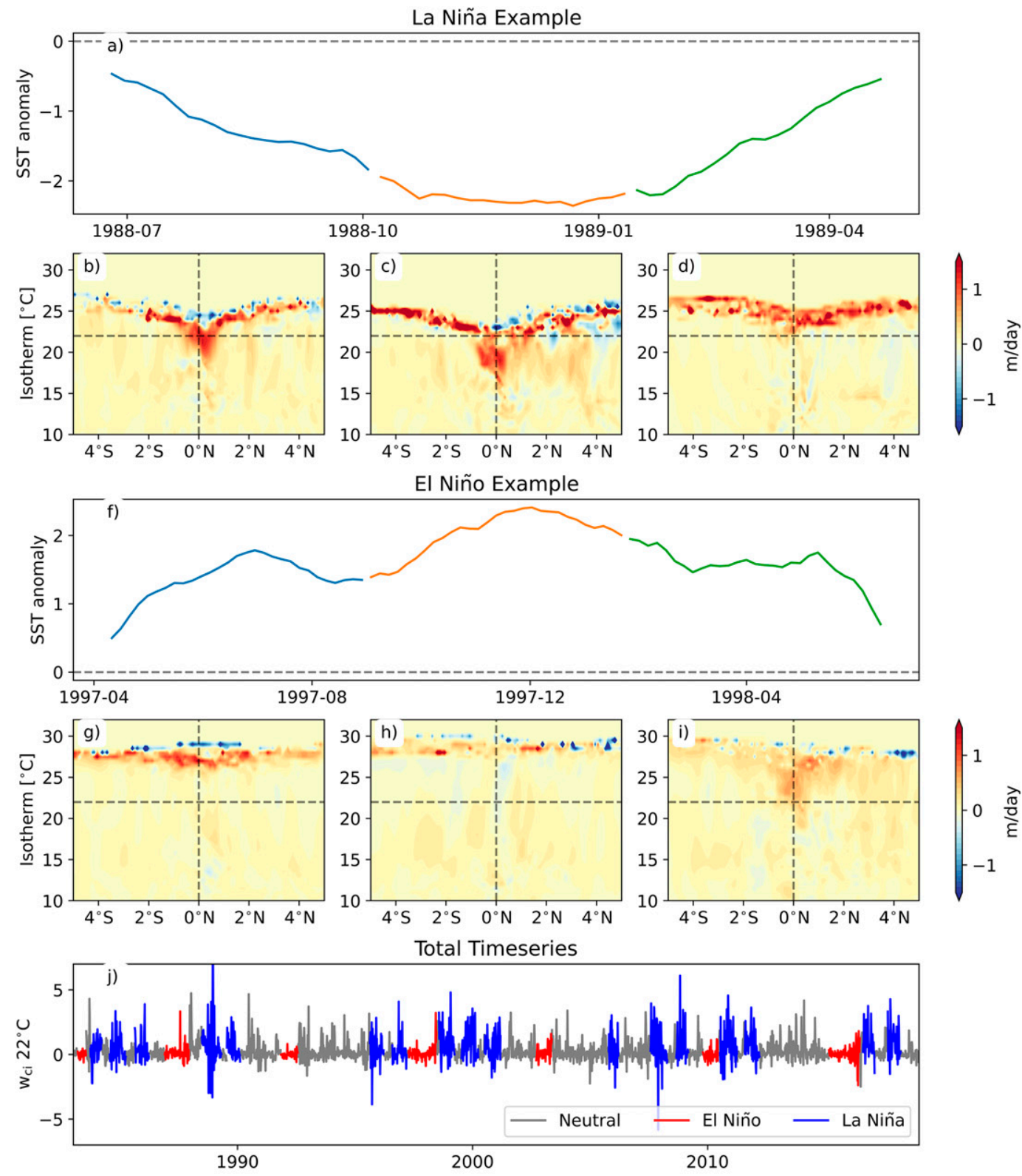

Average $\mathrm{w}_{\mathrm{ci}}$ in column with longitude

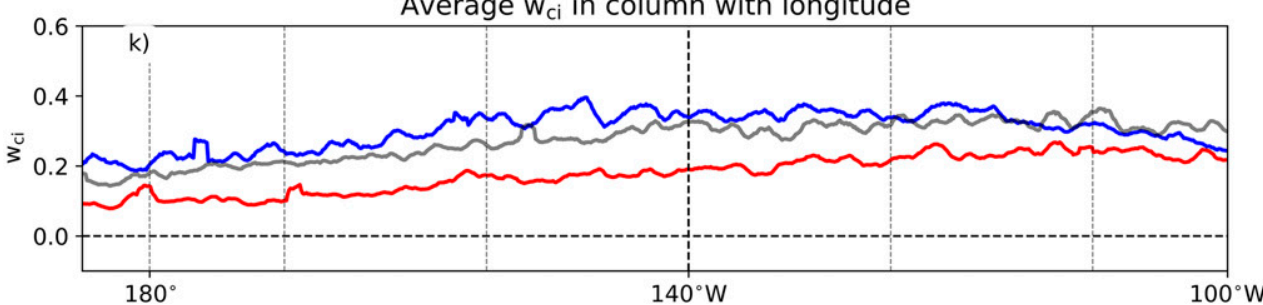

FIG. 6. Examples of $w_{\mathrm{ci}}$ modulation with ENSO in POP2 at $140^{\circ} \mathrm{W}$ during La Niña and El Niño. Shown are the SST time series of the (a) La Niña or (f) El Niño event, separated into buildup (blue), maintenance (orange), and discharge (green) periods. Also shown is the corresponding $w_{\mathrm{ci}}$ modulation with ENSO at $140^{\circ} \mathrm{W}$ during the respective three periods in (b)-(d) La Niña and (g)-(i) El Niño. In (b)-(d) and (g)-(i), horizontal lines show the location of the $22^{\circ} \mathrm{C}$ isotherm and the vertical lines show the equator, for orientation. (j) The 5-day time series of cross-isothermal velocity across the $22^{\circ} \mathrm{C}$ isotherm at $0^{\circ}, 140^{\circ} \mathrm{W}$. (k) The dependence of cross-isothermal velocity ( $\mathrm{m} \mathrm{day}^{-1}$ ) modulation with ENSO on longitude in the form of column averages for the different phases along the equator [same legend as (j)]. Vertical lines in $(\mathrm{k})$ denote the locations $110^{\circ}, 125^{\circ}, 140^{\circ}, 155^{\circ}$, and $170^{\circ} \mathrm{W}$ and $180^{\circ}$, for orientation. 

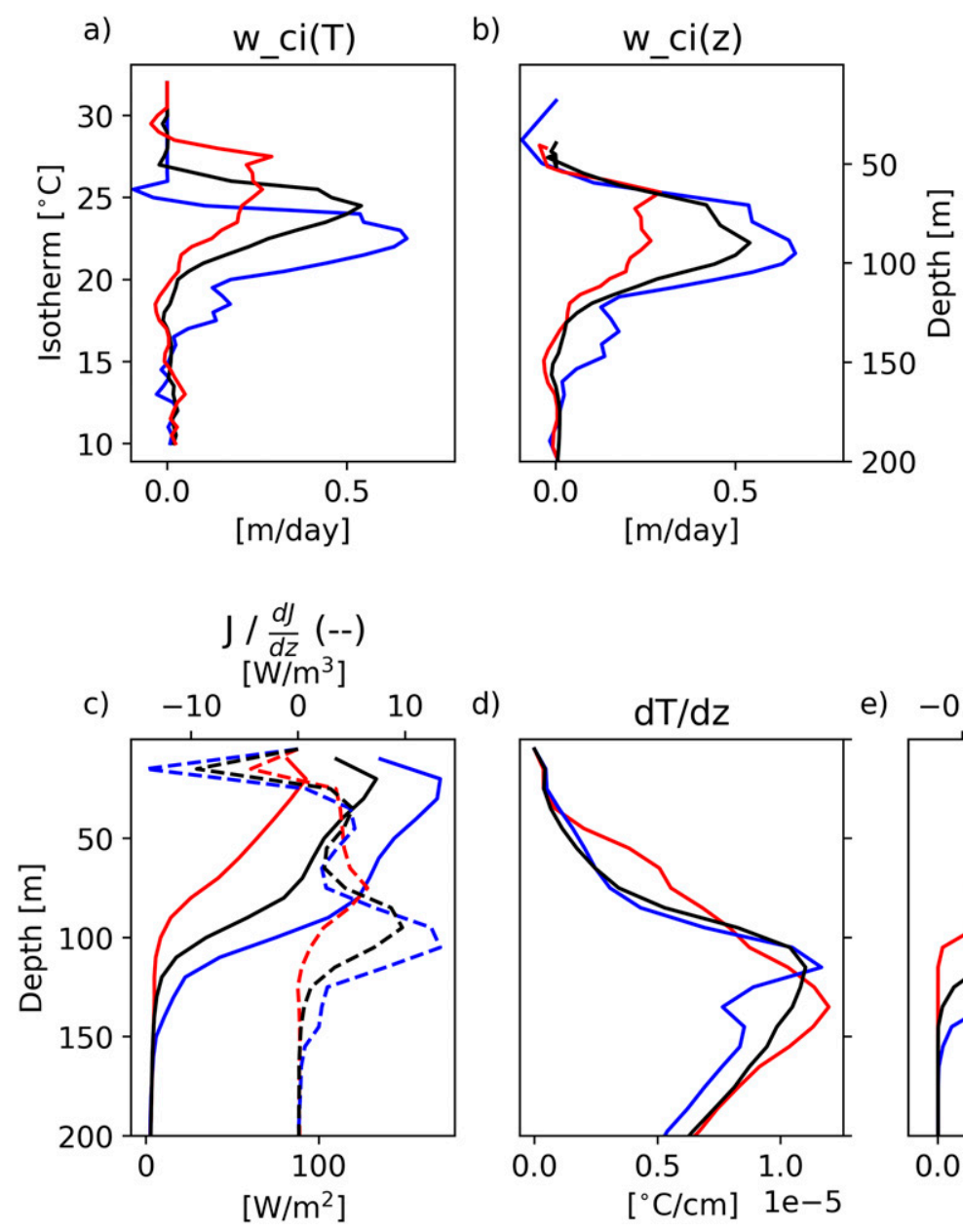

d)

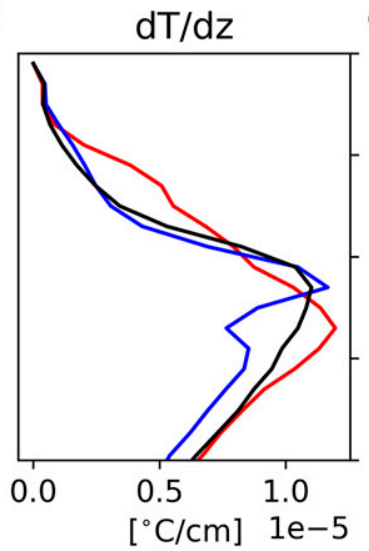

$[1 / \mathrm{s}]$

e) $\quad-0.02 \quad 0.00 \quad 0.02$

FIG. 7. POP 2 profiles at $0^{\circ}, 140^{\circ} \mathrm{W}$ for El Niño (red), La Niña (blue), and neutral (black) conditions, showing cross-isothermal velocity in (a) temperature and (b) depth space, (c) the flux due to vertical mixing (solid; $\mathrm{W} \mathrm{m}^{-2}$ ) and its divergence (dashed; $\mathrm{W} \mathrm{m}^{-3}$ ), (d) the vertical temperature gradient $\left({ }^{\circ} \mathrm{C} \mathrm{cm}^{-1}\right.$ ), and (e) model diffusivity $\kappa\left(\right.$ solid; $\left.\mathrm{m}^{2} \mathrm{~s}^{-1}\right)$ and the absolute mean vertical shear of the zonal velocity (dashed; $\mathrm{s}^{-1}$ ).

frequency and $S$ is the vertical velocity shear; Fig. 8e), which can enable mixing. In POP shear mixing is implemented below values of $\mathrm{Ri}=0.8$ (second gray dashed line in Fig. 8e), rather than the usual value of $\mathrm{Ri}=0.25$ (first gray dashed line in Fig. 8e). The enhanced vertical shear stems mostly from the zonal component of the flow (Figs. 8a,b).

We note that in addition to the increased shear and slightly reduced mean stability, POP frequently produces convective mixing events due to density inversions during La Niña phases $(25 \%$ of the time during La Niña as compared to $8 \%$ of the time during El Niño and $10 \%$ during neutral conditions, diagnosed from a shorter run with hourly output, not shown). This strong mixing enhances the mean diffusivity. Since we cannot be certain that these events occur with similar frequency in the real world (they might be a result of the model numerical scheme), we have tested whether filtering out all occurrences of strong convective mixing influences the results, and we find that the dependence of $w_{\mathrm{ci}}$ on ENSO phase remains the same (not shown).

\section{Discussion and conclusions}

In this study we calculate cross-isothermal velocities $w_{\text {ci }}$ from high temporal and horizontal resolution (5-day averages; $0.1^{\circ}$ ) global ocean model output. The model has been forced with realistic surface fluxes, and we calculate climatological mean $w_{\mathrm{ci}}$ from 5-day averaged heat budget terms and $w_{\mathrm{ci}}$ modulation during ENSO phases.

Our method allows a description of how $w_{\mathrm{ci}}$ varies in space across and along the equator, which physical processes lead to local water mass transformation (WMT), and how it is modulated during large-scale changes. Here, we focus on how physical regime changes related to ENSO modulate WMT at $0^{\circ}, 140^{\circ} \mathrm{W}$. In the thermocline, where the three-dimensional temperature gradient is largely vertical, cross-isothermal velocities $\left(w_{\mathrm{ci}}\right)$ describe diabatic vertical motion, which can be 

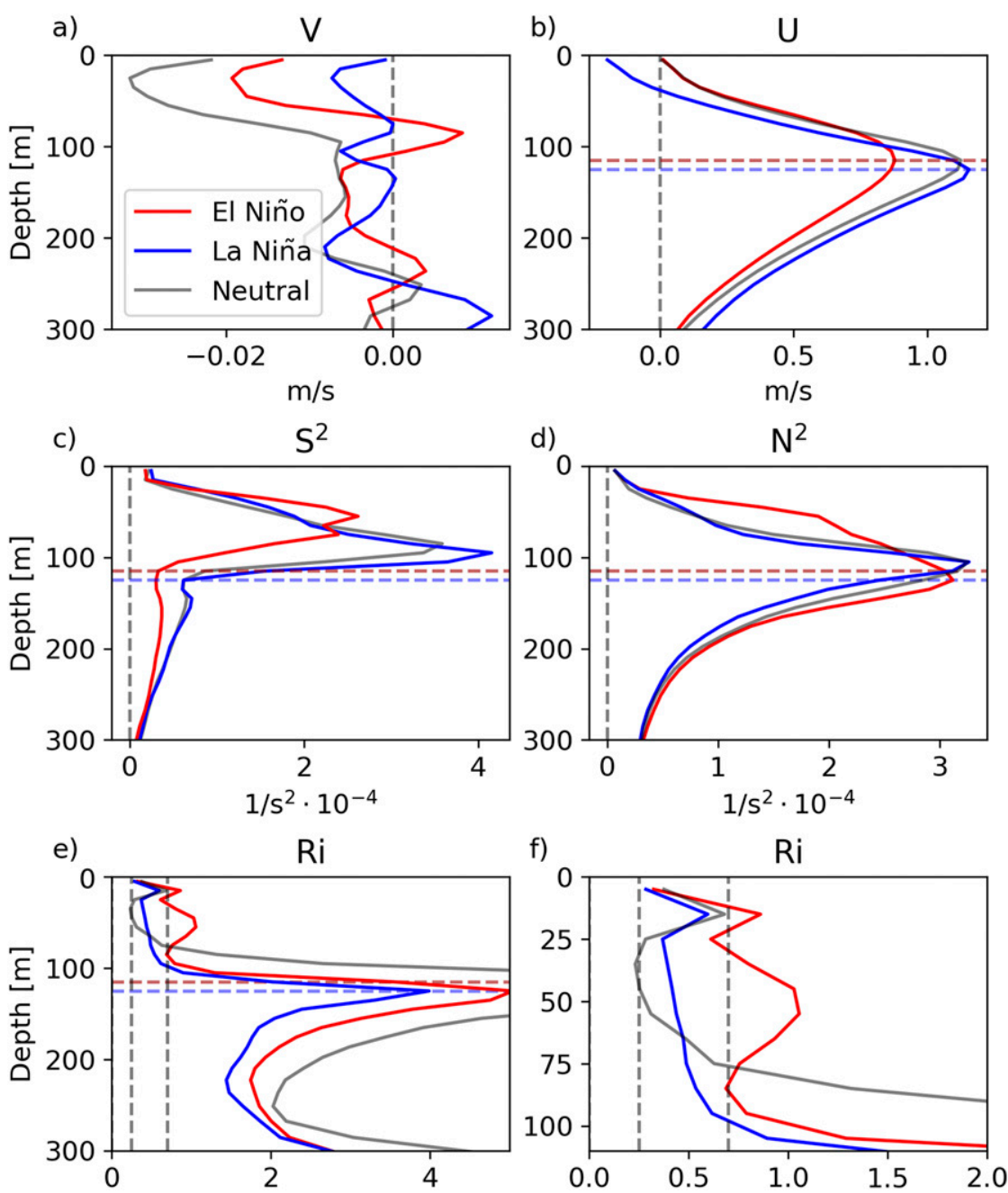

FIG. 8. POP2 profiles at $0^{\circ}, 140^{\circ} \mathrm{W}$ for $\mathrm{El} \mathrm{Niño} \mathrm{(red),} \mathrm{La} \mathrm{Niña} \mathrm{(blue),} \mathrm{and} \mathrm{neutral} \mathrm{(black)}$ conditions: (a) meridional and (b) zonal velocity components and (c) total shear squared and (d) buoyancy squared, from which (e) the gradient Richardson number Ri is calculated [also shown (f)zoomed in on the upper $100 \mathrm{~m}$ ]. Dashed horizontal lines show the depth of the EUC maximum per ENSO condition.

separated from the adiabatic displacement of parcels along isotherms. The diabatic component of vertical motion makes up to one-third of the total vertical motion, which leaves twothirds as adiabatic vertical flow (Fig. 2e). This partitioning holds in the mean, as well as for the different ENSO phases, during which Eulerian vertical velocities are modulated similarly to diabatic velocities (not shown).

These results compare well to Bryden and Brady (1985) and Meinen et al. (2001). Bryden and Brady (1985) find that $1 / 3$ of upward transport crosses the $23^{\circ} \mathrm{C}$ isotherm; Meinen et al. (2001) find a similar fraction. On the other hand, Weisberg and Qiao (2000) report diapycnal transport at a rate similar to the kinematic transport but note that this estimate is based on velocity and isotherm slopes sampled at different scales, which might lead to larger error margins. Their point estimates are larger than our values at $0^{\circ}, 140^{\circ} \mathrm{W}$. In contrast to the large estimate derived by Weisberg and Qiao (2000) and Brown and
Fedorov (2010) find that the contribution of diapycnal transport to interannual variability is negligible, while they find nonnegligible values in the mean. We find a significant fraction of the total velocity to be cross-isothermal, as well as distinct modulation during ENSO phases. Brown and Fedorov (2010) used a coarser ocean model with less vertical layers (36 as opposed to 62 in POP2) and a different parameterization scheme for the ocean vertical mixing. Furthermore, the shear in Brown and Fedorov (2010) is biased low, which reduces shear-driven mixing. This might explain some of the differences, and highlights the importance of testing the robustness of results on diapycnal/diathermal processes in different models.

Averaging POP2 $w_{\mathrm{ci}}$ over the box used in (Meinen et al. 2001 ), i.e., $5^{\circ} \mathrm{S}-5^{\circ} \mathrm{N}, 155^{\circ} \mathrm{W}-95^{\circ} \mathrm{W}$, yields values of the same order of magnitude, but a little larger than what Meinen et al. (2001) found (Fig. 9). The sign of the mean $w_{\mathrm{ci}}$ in our analysis is always positive, in contrast to the observational studies cited 


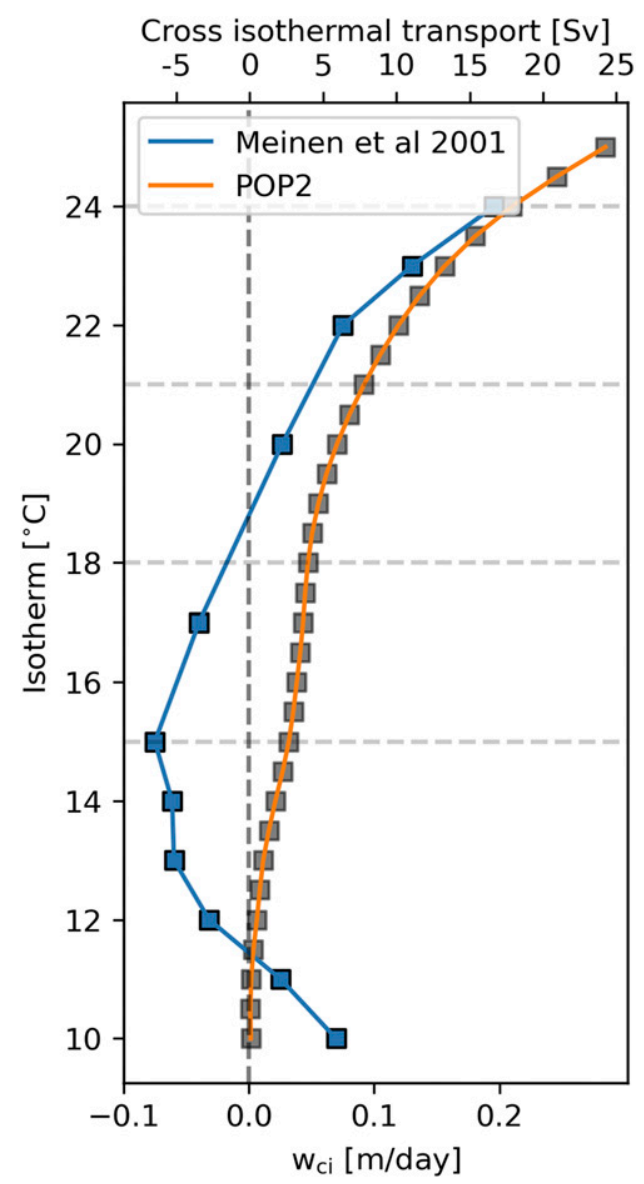

FIG. 9. Comparison $w_{\mathrm{ci}}$ over the Meinen et al. (2001) box $5^{\circ} \mathrm{S}-$ $5^{\circ} \mathrm{N}, 155^{\circ}-95^{\circ} \mathrm{W}$ in temperature space [values from Meinen et al. (2001); this figure was provided by C. Meinen].

above, which find mean downwelling $w_{\mathrm{ci}}$ below depths of $100 \mathrm{~m}$ (Fig. 9). This discrepancy exists in the Eulerian mean $w$, as well. The model simulation does not produce mean downwelling below the EUC. We demonstrate in this manuscript that $w_{\mathrm{ci}}$ in the thermocline is driven by the divergence of the vertical mixing induced heat flux $J$. For $w_{\mathrm{ci}}$ to change sign again, $J$ would have to increase below the EUC, for which an energy source would be required. We note that there are instantaneous values of downwelling, both in $w$ (not shown) and $w_{\text {ci }}$ (Fig. 6j).

We present the cross-isothermal velocity $w_{\mathrm{ci}}$ in temperature space. In depth space, long term averages of this signal would be blurred by the large adiabatic vertical excursions of isopycnal from thermocline heave. The $22^{\circ} \mathrm{C}$ isotherm, for example, almost always lies in the thermocline, while the depth of the thermocline (and therefore the depth of the $22^{\circ} \mathrm{C}$ isotherm) varies from about 70 to $170 \mathrm{~m}$ (see contours in Figs. 2a,b for the depth differences of the $22^{\circ} \mathrm{C}$ isotherms between $\mathrm{El}$ Niño and La Niña). For shallower isotherms, $w_{\text {ci }}$ as a function of temperature can only be calculated when those isotherms exist (see Fig. 10c). To create a quantity that can be compared with the Eulerian $w$ with units of meters per second, we calculate the cumulative displacement of individual isotherms owing to diabatic processes over a specified period of time, and then divide by the length of that time period. In the thermocline, where the isotherms are always present, this does not affect the results. Close to the surface, where (warm) isotherms occur intermittently, averaging over the entire record length means that cumulative transformations across these temporary isotherms may count little for the total displacement of water, depending on how long they exist in the record. We include a comparison between the two averages, averaging over the time the isotherm exists only (Fig. 10a), and the entire record length (Fig. 10b). The difference is largest in the warmest layers, where isotherms may only exist during a small fraction of the total simulation (Fig. 10c). For long-term records it makes sense to account for the cumulative effect of WMT. However, during a field campaign of limited duration, one might expect results rather like Fig. 10a than Fig. 10b.

We investigate the physical drivers that lead to crossisothermal motion in the eastern equatorial Pacific. In the shallowest layer, cross-isothermal velocities become meridional rather than vertical, according to the horizontal direction of the temperature gradient. In this layer, two large effects tend to cancel: downward solar penetration decreases with depth, inducing positive (in this region poleward) $w_{\mathrm{ci}}^{\text {solar }}$."Vertical" mixing in the shallowest layer acts against this effect, acting to move warmer water "down" (equatorward; note blue shading in Fig. 4b). Cross-isothermal velocity $w_{\text {ci }}^{\text {solar }}$ dominates, resulting in WMT along the temperature gradient (transformation from low to high temperatures). This balancing of solar penetration and mixing has also been stressed by Iudicone et al. (2008) and Lengaigne et al. (2012).

In the thermocline, at $140^{\circ} \mathrm{W}$ nominally at temperatures of $18^{\circ}-25^{\circ} \mathrm{C}, w_{\mathrm{ci}}^{\mathrm{vmix}}$ is the dominant contributor to $w_{\mathrm{ci}}$, and therefore drives the bulk of WMT. Cross-isothermal velocity $w_{\mathrm{ci}}^{\mathrm{vmix}}$ changes sign from the surface to the interior, because the gradient of the heat flux due to vertical mixing changes sign: $J$ increases with depth until $\approx 30 \mathrm{~m}$, then decreases downward. The gradient of $J$ indicates the sign and strength of WMT due to vertical mixing [see the first term on the RHS of the second line of (9)]. In the shallowest (warmest) layer, the effect of $w_{\mathrm{ci}}^{\mathrm{vmix}}$ is that water crosses mean isotherms from warm to cold, but in the thermocline $w_{\mathrm{ci}}^{\text {vmix }}$ crosses mean isotherms from cold to warm.

Horizontal diffusion, eddy rectification, and higher-order term effects on $w_{\mathrm{ci}}$ are orders of magnitude smaller than $w_{\mathrm{ci}}^{\text {solar }}$ and $w_{\mathrm{ci}}^{\mathrm{vmix}}$, when basing the calculations on 5-day averages. Because the heat budget terms are averaged at each time step and then saved as 5-daily means, the full effect of TIW on $w_{\mathrm{ci}}^{\mathrm{vmix}}$ is resolved, rather than represented by an "eddy mixing" parameterization one would expect represented in the eddy rectification term. The small eddy rectification term in our calculation only comprises sub-5-day eddies, which are weak in the mean (not shown). With the 5-day averaged heat budget terms we resolve the mixing that results from eddy stirring induced by TIW. TIW increase vertical mixing due to increasing temperature gradients and current shear (Holmes and Thomas 2015). Separation of the effect of TIW would be possible, but it requires different averaging windows. We note that the TIW in this model are weaker than observed by a 

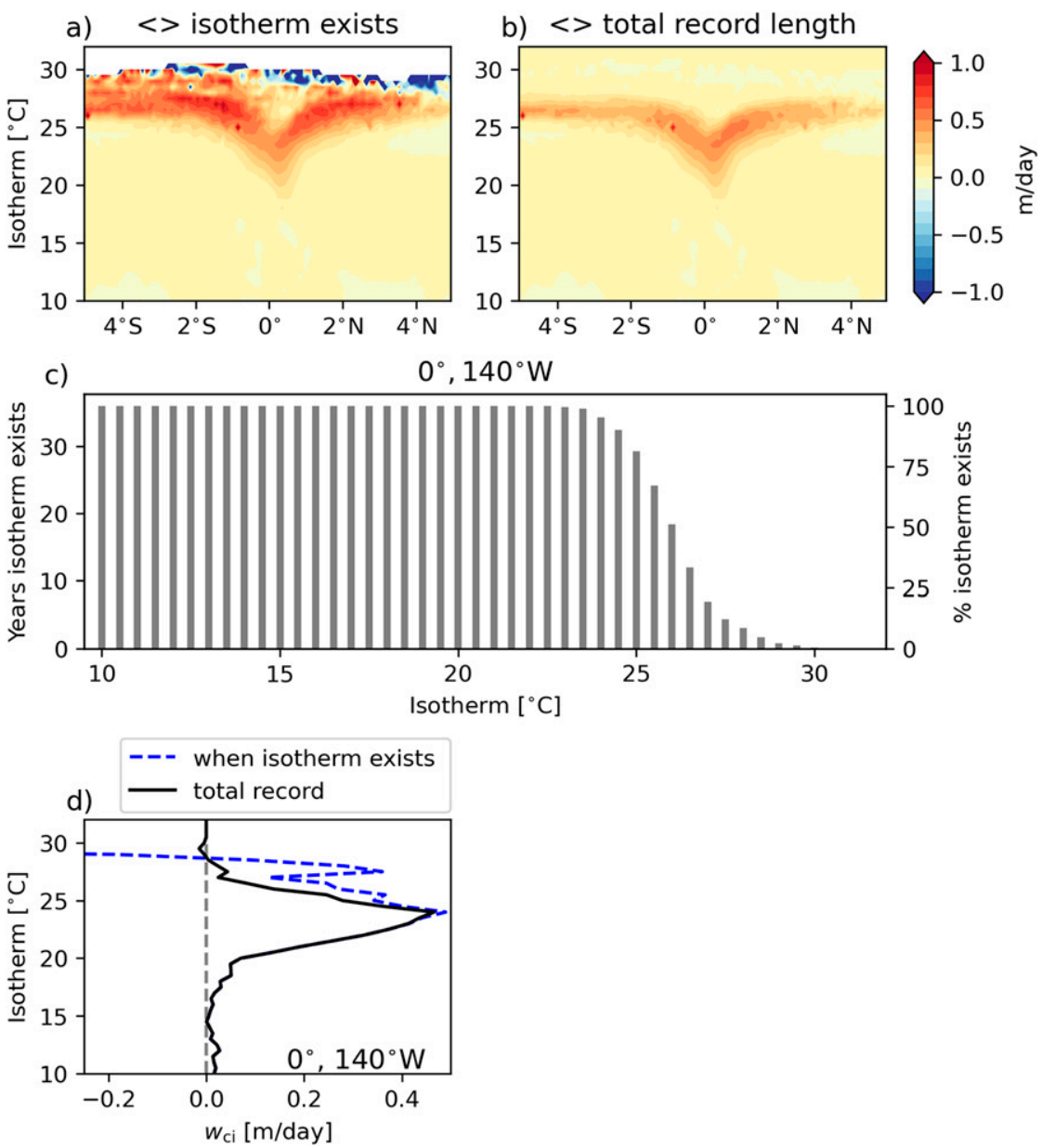

FIG. 10. The 36-yr average of the total cross-isothermal velocity at $140^{\circ} \mathrm{W}$ across the equator. (a) An average that takes into account each point only when the isotherm exists, which leads to larger values close to the surface where isotherms are present only during some periods. (b) The total sum of $w_{\mathrm{ci}}$ at a given point divided by the entire record length, regardless of whether that isotherm exists at all times. (c) The amount of time that a given isotherm exists throughout the record at $0^{\circ}, 140^{\circ} \mathrm{W}$ (the left $y$ axis is in years, and the right $y$ axis is in percent of time). (d) The difference of $w_{\mathrm{ci}}$ at $0^{\circ}, 140^{\circ} \mathrm{W}$ between the two averaging methods. All panels display derived quantities from POP2 model output.

factor of 2. This is despite the relatively realistic representation of the EUC (Fig. 1). Rather it is due to a weak south equatorial countercurrent north of the equator and a weak equatorial countercurrent (not shown). This is at least partly attributed to deficiencies in the representation of wind stress curl in the JRA-55do forcing product (Sun et al. 2019). These errors in forcing result in a weak meridional shear north of the equator, which in turn leads to reduced instability. However, we note that there are significant asymmetries across the equator indicating that TIWs are present. For instance, in Figs. $5 \mathrm{e}-\mathrm{g}$ positive $w_{\mathrm{ci}}$ extend farther north of the equator than south, especially in Fig. 5g. This is consistent with TIWs being more active during La Niña than during El Niño. The same argument holds for Fig. $6 c$. Modulation of $w_{\text {ci }}$ on subannual time scales, such as with TIW and the seasonal cycle, are the subject of a future study.
We find that $w_{\mathrm{ci}}$ increases overall during La Niña because of enhanced shear due to the large-scale adjustments of the circulation: strengthening of the EUC (Fig. 8b), and relatively strong westward surface currents. Stability throughout the column is reduced, with only a thin stable layer in the EUC core during La Niña (Fig. 8e). The combined effect of increased shear and reduced stability leads to decreased Richardson number, with consequently enhanced vertical mixing. These results are consistent with Lengaigne et al. (2012), who found that diabatic processes contribute more than $70 \%$ to the buildup of water volume leading to $\mathrm{La}$ Niña events.

During El Niño, WMT almost entirely collapses, leaving a larger role to play for adiabatic processes. Eastward surface current anomalies reduce vertical shear above the EUC core, while warmer upper-layer temperatures increase stability. 
These results indicate that the heat uptake in the cold tongue, which has been argued to play a dominant role in closing the heat and water mass transformation budget of the global ocean (Newsom and Thompson 2018; Holmes et al. 2019b), occurs mainly during La Niña and normal years, and is significantly diminished during El Niño. Observational evidence for the reduced heat flux during El Niño has recently been shown by Warner and Moum (2019).

This analysis points to the importance of vertical mixing, which is a parameterized process in climate models. The estimates presented here for $w_{\mathrm{ci}}$ and turbulent heat flux variability agrees well with the limited literature available (Holmes et al. 2019a; Huguenin et al. 2020). However, more observational constraints are necessary to quantify these vital processes, build confidence in the parameterizations, and improve upon them. Vertically resolved profiles between $2^{\circ} \mathrm{S}$ and $2^{\circ} \mathrm{N}$ extending to at least $150 \mathrm{~m}$ depth of temperature, velocity, and, importantly, turbulent heat flux are needed to verify and validate our model.

Acknowledgments. This study was supported by the National Center for Atmospheric Research, which is a major facility sponsored by the National Science Foundation under Cooperative Agreement 1852977, and by the NOAA Climate Variability Program under Grant Agreement NA18OAR4310399. This work is part of the CVP TPOS 2020 prefield modeling effort lead by Dr. Sandy Lucas and is PMEL Contribution Number 5154. Computing resources were provided by the Climate Simulation Laboratory at NCAR's Computational and Information Systems Laboratory. TAO observational data were made available by the GTMBA Project Office of NOAA/PMEL (https://www.pmel.noaa.gov/tao/drupal/disdel/). The authors gratefully acknowledge Dr. Christopher Meinen for providing estimates of $w_{\text {ci }}$ from Meinen et al. (2001), and Dr. Deepak Cherian for valuable help during the software development process.

\section{REFERENCES}

Barnston, A. G., M. K. Tippett, M. L. L'Heureux, S. Li, and D. G. DeWitt, 2012: Skill of real-time seasonal ENSO model predictions during 2002-11: Is our capability increasing? Bull. Amer. Meteor. Soc., 93, 631-651, https://doi.org/10.1175/ BAMS-D-11-00111.1.

Bayr, T., D. I. Domeisen, and C. Wengel, 2019: The effect of the equatorial Pacific cold SST bias on simulated ENSO teleconnections to the North Pacific and California. Climate Dyn., 53, 3771-3789, https://doi.org/10.1007/s00382019-04746-9.

Brown, J. N., and A. V. Fedorov, 2010: Estimating the diapycnal transport contribution to warm water volume variations in the tropical Pacific Ocean. J. Climate, 23, 221-237, https://doi.org/ 10.1175/2009JCLI2347.1.

Bryan, F., and S. Bachman, 2015: Isohaline salinity budget of the North Atlantic salinity maximum. J. Phys. Oceanogr., 45, 724-736, https://doi.org/10.1175/JPO-D-14-0172.1.

Bryden, H. L., and E. C. Brady, 1985: Diagnostic model of the three-dimensional circulation in the upper equatorial Pacific Ocean. J. Phys. Oceanogr., 15, 1255-1273, https://doi.org/ 10.1175/1520-0485(1985)015<1255:DMOTTD>2.0.CO;2.
Boyer, T. P., and Coauthors, 2013: World Ocean Database 2013. NOAA Atlas NESDIS 72, 209 pp., http://doi.org/10.7289/ V5NZ85MT.

Chang, P., and Coauthors, 2006: Climate fluctuations of tropical coupled systems-The role of ocean dynamics. J. Climate, 19, 5122-5174, https://doi.org/10.1175/JCLI3903.1.

Chassignet, E. P., and Coauthors, 2020: Impact of horizontal resolution of global ocean-sea ice model simulations based on the experimental protocols of the Ocean Model Intercomparison Project phase 2 (OMIP-2). Geosci. Model Dev., 13, 4595-4637, https://doi.org/10.5194/gmd-13-4595-2020.

Cromwell, T., 1953: Circulation in a meridional plane in the central equatorial Pacific. J. Mar. Res., 12, 196-213.

— undercurrent in Pacific Ocean revealed by new methods. Science, 119, 648-649, https://doi.org/10.1126/science.119.3097.648.

Ding, H., M. Newman, M. A. Alexander, and A. T. Wittenberg, 2020: Relating CMIP5 model biases to seasonal forecast skill in the tropical Pacific. Geophys. Res. Lett., 47, e2019GL086765, https://doi.org/10.1029/2019GL086765.

England, M. H., and Coauthors, 2014: Recent intensification of wind-driven circulation in the Pacific and the ongoing warming hiatus. Nat. Climate Change, 4, 222-227, https://doi.org/ 10.1038/nclimate2106.

Groeskamp, S., S. M. Griffies, D. Iudicone, R. Marsh, A. G. Nurser, and J. D. Zika, 2019: The water mass transformation framework for ocean physics and biogeochemistry. Annu. Rev. Mar. Sci., 11, 271-305, https://doi.org/10.1146/annurev-marine-010318-095421.

Hieronymus, M., J. Nilsson, and J. Nycander, 2014: Water mass transformation in salinity-temperature space. J. Phys. Oceanogr., 44, 2547-2568, https://doi.org/10.1175/JPO-D-13-0257.1.

Holmes, R. M., and L. Thomas, 2015: The modulation of equatorial turbulence by tropical instability waves in a regional ocean model. J. Phys. Oceanogr., 45, 1155-1173, https://doi.org/ 10.1175/JPO-D-14-0209.1.

, J. D. Zika, and M. H. England, 2019a: Diathermal heat transport in a global ocean model. J. Phys. Oceanogr., 49, 141-161, https:// doi.org/10.1175/JPO-D-18-0098.1.

, R. Ferrari, A. F. Thompson, E. R. Newsom, and M. H. England, 2019b: Atlantic Ocean heat transport enabled by Indo-Pacific heat uptake and mixing. Geophys. Res. Lett., 46, 13 939-13 949, https://doi.org/10.1029/2019GL085160.

Huguenin, M. F., R. M. Holmes, and M. H. England, 2020: Key role of diabatic processes in regulating warm water volume variability over ENSO events. J. Climate, 33, 9945-9964, https:// doi.org/10.1175/JCLI-D-20-0198.1.

Iudicone, D., G. Madec, and T. J. McDougall, 2008: Water-mass transformations in a neutral density framework and the key role of light penetration. J. Phys. Oceanogr., 38, 1357-1376, https://doi.org/10.1175/2007JPO3464.1.

Ji, M., and A. Leetmaa, 1997: Impact of data assimilation on ocean initialization and El Nino prediction. Mon. Wea. Rev., 125, 742-753, https://doi.org/10.1175/1520-0493(1997)125<0742: IODAOO $>2.0 . \mathrm{CO} ; 2$.

Jin, F.-F., 1997: An equatorial ocean recharge paradigm for ENSO. Part I: Conceptual model. J. Atmos. Sci., 54, 811-829, https:// doi.org/10.1175/1520-0469(1997)054<0811:AEORPF>2.0.CO;2.

Johnson, G. C., M. J. McPhaden, and E. Firing, 2001: Equatorial Pacific Ocean horizontal velocity, divergence, and upwelling. J. Phys. Oceanogr., 31, 839-849, https://doi.org/10.1175/15200485(2001)031<0839:EPOHVD>2.0.CO;2.

Karnauskas, K. B., R. Murtugudde, and A. J. Busalacchi, 2007: The effect of the Galápagos Islands on the equatorial Pacific cold 
tongue. J. Phys. Oceanogr., 37, 1266-1281, https://doi.org/ 10.1175/JPO3048.1.

Kobayashi, S., and Coauthors, 2015: The JRA-55 reanalysis: General specifications and basic characteristics. J. Meteor. Soc. Japan, 93, 5-48, https://doi.org/10.2151/jmsj.2015-001.

Large, W. G., J. C. McWilliams, and S. C. Doney, 1994: Oceanic vertical mixing: A review and a model with a nonlocal boundary layer parameterization. Rev. Geophys., 32, 363-403, https://doi.org/10.1029/94RG01872.

Lengaigne, M., U. Hausmann, G. Madec, C. Menkès, J. Vialard, and J.-M. Molines, 2012: Mechanisms controlling warm water volume interannual variations in the equatorial Pacific: Diabatic versus adiabatic processes. Climate Dyn., 38, 1031-1046, https://doi.org/10.1007/s00382-011-1051-z.

Lien, R.-C., D. R. Caldwell, M. Gregg, and J. N. Moum, 1995: Turbulence variability at the equator in the central Pacific at the beginning of the 1991-1993 El Nino. J. Geophys. Res., 100, 6881-6898, https://doi.org/10.1029/94JC03312.

McPhaden, M. J., S. E. Zebiak, and M. H. Glantz, 2006: ENSO as an integrating concept in Earth science. Science, 314, 1740-1745, https://doi.org/10.1126/science.1132588.

Mechoso, C. R., and Coauthors, 1995: The seasonal cycle over the tropical Pacific in coupled ocean-atmosphere general circulation models. Mon. Wea. Rev., 123, 2825-2838, https://doi.org/ 10.1175/1520-0493(1995)123<2825:TSCOTT>2.0.CO;2.

Meinen, C. S., and M. J. McPhaden, 2000: Observations of warm water volume changes in the equatorial Pacific and their relationship to El Niño and La Niña. J. Climate, 13, 3551-3559, https://doi.org/10.1175/1520-0442(2000)013<3551: OOWWVC $>2.0 . \mathrm{CO} ; 2$.

— , and — 2001: Interannual variability in warm water volume transports in the equatorial Pacific during 1993-99. J. Phys. Oceanogr., 31, 1324-1345, https://doi.org/10.1175/ 1520-0485(2001)031<1324:IVIWWV >2.0.CO;2.

—_, - - and G. C. Johnson, 2001: Vertical velocities and transports in the equatorial Pacific during 1993-99. J. Phys. Oceanogr., 31, 3230-3248, https://doi.org/10.1175/15200485(2001)031<3230:VVATIT >2.0.CO;2.

Moum, J., and J. Nash, 2009: Mixing measurements on an equatorial ocean mooring. J. Atmos. Oceanic Technol., 26, 317-336, https://doi.org/10.1175/2008JTECHO617.1.

Moum, J. N., D. R. Caldwell, and C. A. Paulson, 1989: Mixing in the equatorial surface layer and thermocline. J. Geophys. Res., 94, 2005-2022, https://doi.org/10.1029/ JC094iC02p02005.

_ _ A. Perlin, J. D. Nash, and M. J. McPhaden, 2013: Seasonal sea surface cooling in the equatorial Pacific cold tongue controlled by ocean mixing. Nature, 500, 64-67, https://doi.org/10.1038/ nature12363.

Neelin, J. D., D. S. Battisti, A. C. Hirst, F.-F. Jin, Y. Wakata, T. Yamagata, and S. E. Zebiak, 1998: ENSO theory. J. Geophys. Res., 103, 14 261-14 290, https://doi.org/10.1029/ 97JC03424.

Newsom, E. R., and A. F. Thompson, 2018: Reassessing the role of the Indo-Pacific in the ocean's global overturning circulation. Geophys. Res. Lett., 45, 12 422-12 431, https://doi.org/10.1029/ 2018GL080350.

Niiler, P., and J. Stevenson, 1982: The heat budget of tropical ocean warm-water pools. J. Mar. Res., 40, 465-480.

Nurser, A., R. Marsh, and R. G. Williams, 1999: Diagnosing water mass formation from air-sea fluxes and surface mixing. J. Phys. Oceanogr., 29, 1468-1487, https://doi.org/10.1175/ 1520-0485(1999)029<1468:DWMFFA>2.0.CO;2.
Ohlmann, J. C., 2003: Ocean radiant heating in climate models. J. Climate, 16, 1337-1351, https://doi.org/10.1175/1520-044216.9.1337.

Philander, S. G. H., 1990: El Nino, La Nina, and the Southern Oscillation. International Geophysics Series, Vol. 46, Academic Press, 293 pp.

Ray, S., A. T. Wittenberg, S. M. Griffies, and F. Zeng, 2018: Understanding the equatorial Pacific cold tongue time-mean heat budget. Part II: Evaluation of the GFDL-FLOR coupled GCM. J. Climate, 31, 9987-10011, https://doi.org/10.1175/ JCLI-D-18-0153.1.

Samanta, D., K. B. Karnauskas, and N. F. Goodkin, 2019: Tropical Pacific SST and ITCZ biases in climate models: Double trouble for future rainfall projections? Geophys. Res. Lett., $\mathbf{4 6}$, 2242-2252, https://doi.org/10.1029/2018GL081363.

Smith, R., and Coauthors, 2010: The Parallel Ocean Program (POP) reference manual: Ocean component of the Community Climate System Model (CCSM). Los Alamos National Laboratory Tech. Rep. LAUR-10-01853, 140 pp., https://opensky.ucar.edu/ islandora/object/manuscripts \%3A825/.

Smyth, W., and J. Moum, 2013: Marginal instability and deep cycle turbulence in the eastern equatorial Pacific Ocean. Geophys. Res. Lett., 40, 6181-6185, https://doi.org/10.1002/ 2013 GL058403.

Sun, Z., H. Liu, P. Lin, Y. Tseng, J. Small, and F. Bryan, 2019: The modeling of the north equatorial countercurrent in the Community Earth System Model and its oceanic component. J. Adv. Model. Earth Syst., 11, 531-544, https://doi.org/ 10.1029/2018MS001521.

Tang, Y., and Coauthors, 2018: Progress in ENSO prediction and predictability study. Natl. Sci. Rev., 5, 826-839, https://doi.org/ 10.1093/nsr/nwy105.

Timmermann, A., and Coauthors, 2018: El Niño-Southern Oscillation complexity. Nature, 559, 535-545, https://doi.org/ 10.1038/s41586-018-0252-6.

Toole, J. M., H.-M. Zhang, and M. J. Caruso, 2004: Timedependent internal energy budgets of the tropical warm water pools. J. Climate, 17, 1398-1410, https://doi.org/ 10.1175/1520-0442(2004)017<1398:TIEBOT>2.0.CO;2.

Tsujino, H., and Coauthors, 2018: JRA-55 based surface dataset for driving ocean-sea-ice models (JRA55-do). Ocean Modell., 130, 79-139, https://doi.org/10.1016/j.ocemod.2018.07.002.

Viúdez, A., 2000: Volume and mass transport across isosurfaces of a balanced fluid property. J. Phys. Oceanogr., 30, 1478-1485, https://doi.org/10.1175/1520-0485(2000)030<1478: VAMTAI $>2.0 . \mathrm{CO} ; 2$.

Walin, G., 1982: On the relation between sea-surface heat flow and thermal circulation in the ocean. Tellus, 34, 187-195, https:// doi.org/10.3402/tellusa.v34i2.10801.

Wang, C., C. Deser, J.-Y. Yu, P. DiNezio, and A. Clement, 2017: El Niño and Southern Oscillation (ENSO): A review. Coral Reefs of the Eastern Tropical Pacific, Springer, 85-106.

Wang, W., and M. J. McPhaden, 1999: The surface-layer heat balance in the equatorial Pacific Ocean. Part I: Mean seasonal cycle. J. Phys. Oceanogr., 29, 1812-1831, https://doi.org/ 10.1175/1520-0485(1999)029<1812:TSLHBI >2.0.CO;2.

—, and — 2000: The surface-layer heat balance in the equatorial Pacific Ocean. Part II: Interannual variability. J. Phys. Oceanogr., 30, 2989-3008, https://doi.org/10.1175/ 1520-0485(2001)031<2989:TSLHBI>2.0.CO;2.

Warner, S. J., and J. N. Moum, 2019: Feedback of mixing to ENSO phase change. Geophys. Res. Lett., 46, 13 920-13 927, https:// doi.org/10.1029/2019GL085415. 
Weisberg, R. H., and L. Qiao, 2000: Equatorial upwelling in the Central Pacific estimated from moored velocity profilers. J. Phys. Oceanogr., 30, 105-124, https://doi.org/10.1175/15200485(2000)030<0105:EUITCP > 2.0.CO;2.

Wyrtki, K., 1975: El Niño-The dynamic response of the equatorial Pacific Ocean to atmospheric forcing. J. Phys. Oceanogr., 5, 572-584, https://doi.org/10.1175/1520-0485(1975)005<0572: ENTDRO $>2.0 . \mathrm{CO} ; 2$.
- 1981: An estimate of equatorial upwelling in the Pacific. J. Phys. Oceanogr., 11, 1205-1214, https://doi.org/10.1175/ 1520-0485(1981)011<1205:AEOEUI >2.0.CO;2.

Zelle, H., G. Appeldoorn, G. Burgers, and G. J. van Oldenborgh, 2004: The relationship between sea surface temperature and thermocline depth in the eastern equatorial Pacific. J. Phys. Oceanogr., 34, 643-655, https://doi.org/10.1175/ 2523.1. 